VILLEGAS, Myrna. "Contribuciones para un concepto de terrorismo en el derecho penal chileno".

Polít. crim. Vol. 11, No 21 (Julio 2016), Art. 6, pp. 140-172.

[http://www.politicacriminal.cl/Vol_11/n_21/Vol11N21A6.pdf]

\title{
Contribuciones para un concepto de terrorismo en el derecho penal chileno*
}

\section{Contributions to a concept of terrorism in Chilean criminal law}

\author{
Myrna Villegas Díaz \\ Doctora en derecho y postgraduada en criminología. Universidad de Salamanca. España. \\ Investigadora Centro de Derechos Humanos Universidad de Chile \\ mvillegas@derecho.uchile.cl.
}

\section{Resumen}

El artículo identifica y examina núcleos problemáticos en el concepto jurídico de terrorismo que deben abordarse en una reforma legal. Basado en legislación internacional y comparada actualizada, describe, sistematiza y analiza distintos modelos de tratamiento jurídico penal del terrorismo y examina algunas propuestas que se han formulado en Chile en los últimos años. Finaliza ofreciendo una visión personal respecto de los elementos que deben considerarse en el tipo penal y su importancia.

Palabras clave: Concepto de terrorismo, crimen organizado, organización terrorista, medios idóneos, causar terror.

\begin{abstract}
The article identifies and examines the core problems in the legal concept of terrorism to be addressed in a legal reform. Based on the international and current comparative law, it describes, systematizes and analyzes the different models of criminal legal treatment of terrorism and examines some proposals that have been made in Chile in recent years. It concludes offering a personal view on the elements that should be considered a criminal offense and their importance.
\end{abstract}

Key words: Concept of terrorism, organized crime, terrorist organization, appropriate means, causing terror.

\section{Introducción}

Una de las problemáticas más difundidas en los últimos años en Chile es la dificultad para identificar jurídicamente un acto de terrorismo en el derecho penal interno. Ella proviene no solo de la imprecisa tipificación en la Ley $\mathrm{N}^{\circ} 18.314$ de 17 de mayo de 1984, Determina conductas terroristas y fija su penalidad, sino de la vaguedad de su concepto a nivel internacional. Esto es particularmente grave si consideramos que bajo el amparo del

\footnotetext{
* Este trabajo ha sido elaborado en el marco del proyecto Fondecyt Regular $2014 \mathrm{~N}^{\circ} 1140040$, titulado: "Terrorismo y democracia. Bases para un concepto jurídico de terrorismo en el derecho penal chileno y examen de núcleos problemáticos en su actual regulación”, del cual la autora es investigadora responsable.
} 
VILLEGAS, Myrna. "Contribuciones para un concepto de terrorismo en el derecho penal chileno".

terrorismo, se justifica un tratamiento sustantivo y procesal agravatorio que en muchas ocasiones viene a sustituir la razón jurídica por la razón de Estado. Razón de Estado que al someter los medios a los fines políticos, transforma la legislación en un verdadero "estado de excepción no declarado"1 reñido con un estado de derecho ${ }^{2}$. Esto es lo que está sucediendo en América del Norte y Europa como reacción a los ataques del terrorismo islámico.

A diferencia de los países del Norte y del Noreste, en América Latina, violencia semejante proviene de la criminalidad organizada (narcotráfico, maras), o de organizaciones que responden a los modelos clásicos de asociaciones ilícitas (Sendero Luminoso, FARC), pero no de violencia con motivaciones político religiosas o separatistas. Luego, ¿será adecuado importar modelos de punición que responden a realidades distintas de la nuestra?

El artículo identifica los principales problemas que deben resolverse antes de decidir la forma en la que debe tratarse jurídicamente el terrorismo en el derecho penal chileno, considerando aspectos criminológicos, político criminales y dogmáticos, para luego ofrecer los elementos esenciales de una alternativa de punición coherente con el respeto a derechos fundamentales. Entre tales problemas están la exigencia a los Estados de definir jurídicamente el terrorismo por una legislación internacional carente de criterios unívocos, la polémica sobre si el terrorismo es siempre organizado o puede ser individual, si siendo organizado es o no "criminalidad organizada", y si debe tratarse como un delito común, como un delito sui generis ${ }^{3}$ o una simple agravante de responsabilidad.

Para el caso en que se decida que debe continuar siendo un delito sui generis, cual es el rol de la organización terrorista, si debe tratarse el terrorismo bajo la forma de delito de organización, o si ésta debe ser un elemento del tipo o de simple punibilidad. Debe abordarse si también es necesario un elemento subjetivo específico en el tipo penal, y en caso de ser afirmativa la respuesta si éste debe o no reflejar una determinada intencionalidad política, o si pudiera ser de otra naturaleza como la de simplemente querer causar temor, pues aquí subyace la problemática respecto del bien jurídico protegido.

\section{La ausencia de un concepto global de terrorismo y sus repercusiones en la legislación internacional y comparada.}

En pleno siglo XXI el concepto de terrorismo sigue sin precisarse por varias razones: la polémica derivada de su naturaleza de delito político, "despolitizado" a efectos de su tratamiento jurídico ${ }^{4}$; la disyuntiva entre violencia de opresión o violencia de

\footnotetext{
1 ZAFFARONI, Raúl, "El antiterrorismo y los mecanismos de desplazamiento" en: SERRANO PIEDECASAS, José Ramón; DEMETRIO, Eduardo (Dirs.), Terrorismo y Estado de derecho, Madrid: Iustel, 2010, pp. 361-380, p. 379.

${ }^{2}$ GRUPO DE ESTUDIOS DE POLITICA CRIMINAL: Una propuesta de renovación de la política criminal sobre terrorismo, Documentos 14 (2013), Valencia: Tirant Lo Blanch, p. 15.

3 Entendido como delito autónomo. MAURACH, Reinhart, Derecho Penal. Parte General. T.I, Trad. BOFILL, Jorge; AIMONE, Enrique, séptima edición, Buenos Aires: Astrea, 1994, p. 363.

4 Ampliamente GUZMÁN DALBORA, José Luis, "El terrorismo como delito común", en: AMBOS, Kai, Terrorismo y Derecho penal, Bogotá: Konrad Adenauer, 2015, pp. 401-438, p. 411-412.
} 
Polít. crim. Vol. 11, No 21 (Julio 2016), Art. 6, pp. 140-172.

[http://www.politicacriminal.cl/Vol_11/n_21/Vol11N21A6.pdf]

emancipación ${ }^{5}$; la carga emotiva que conlleva, la marcada tendencia a catalogar como terrorismo la violencia no estatal para justificar la violencia estatal ${ }^{6}$; la escasez de investigaciones en el campo de las ciencias sociales ${ }^{7}$, que en su mayoría tras el $11 \mathrm{~S}$ se han enfocado hacia un tipo de terrorismo, el islámico. A ello se suma la multiplicidad de formas que puede asumir, pues no puede identificarse el terrorismo internacional con el terrorismo transnacional o con el terrorismo local o interno ${ }^{8}$. La restauración del califato erigido actualmente como Estado Islámico y su paulatina extensión territorial para así poder imponer el Corán sobre el planeta, amenazan la seguridad exterior de los Estados, y no son las mismas que las de la violencia interna, aun cuando ésta tenga cierto grado de internacionalización, p.ej. ETA, IRA, FARC, Sendero Luminoso. El Estado Islámico decapita cristianos, incluidos niños, en nombre del Corán ${ }^{9}$, desplegando un devastador potencial genocida cuyos efectos no pueden compararse con los de las organizaciones mencionadas. Y ninguno de estos dos tipos de violencia es similar a la violencia callejera ${ }^{10}$ denominada "terrorismo doméstico", o "terrorismo urbano" o de baja intensidad".

En sintonía con lo anterior, el sistema jurídico internacional presenta un carácter fragmentario en relación al terrorismo ${ }^{11}$, manifestado en catorce convenios mundiales, que hacen referencia al terrorismo internacional o transnacional, mencionando algunos elementos comunes pero esto no permite identificar un concepto claro ${ }^{12}$, pues la presencia de unos u otros elementos no es copulativa en todos.

\footnotetext{
5 TERRADILlOS BASOCO, Juan, "El Estado de derecho y el fenómeno del terrorismo" en: SERRANO PIEDECASAS, José Ramón; DEMETRIO, Eduardo (Dirs.), Terrorismo y Estado de derecho, Madrid: Iustel, 2010, pp. 271-292, pp. 276-281.

${ }^{6}$ TORRES VÁSQUEZ, Henry, "El concepto de terrorismo. Su inexistencia o inoperancia: La apertura a la violación de derechos humanos", Diálogos y Saberes. Investigaciones en derecho y ciencias sociales, $\mathrm{N}^{\circ} 32$ (2010), pp.77-90, pp.80-81.

${ }^{7}$ LANDA GOROSTIZA, Jon, "La sombra de los crímenes contra la humanidad en la política antiterrorista española: Reflexiones críticas", Revista electrónica de ciencia penal y criminología 12-10 (2010), pp. 1-30, en: http://criminet.ugr.es/recpc, p. 10: 7 [visitado el 02.08.2015]

${ }^{8}$ Para una diferenciación REINARES, Fernando, "Conceptualizando el terrorismo internacional", ARI No 82 (2005), en: http://www.realinstitutoelcano.org/ [visitado el 20.06.2015], PÉREZ CEPEDA, Ana, "Definición del delito de terrorismo como un delito internacional", en: SERRANO PIEDECASAS, José RamónDEMETRIO, Eduardo (Dirs.). Terrorismo y Estado de derecho, Madrid: Iustel, 2010, pp. 53-79, pp. 54-55.

${ }^{9}$ En agosto de 2014 comenzaron las decapitaciones a niños cristianos en un parque en Mossul (Irak), http://www.infobae.com/2014/08/08/1586241-masacre-cristianos-irak-los-yihadistas-decapitan-los-ninos

[visitado el 20.11.2015].

${ }^{10}$ Es el caso de la kale borroka en el País vasco.

${ }^{11}$ ESCRIBANO UBEDA, José, Terrorismo, narcotráfico, blanqueo de capitales, trata de personas, tráfico ilícito de migrantes, tráfico ilícito de armas: Lucha global contra la delincuencia organizada transnacional, Madrid: Visión Libros, 2009, pp. 58 y ss.

${ }^{12}$ Cfr. GARCÍA RIVAS, Nicolás, "La tipificación "europea" del delito terrorista en la Decisión Marco de 2002”. Análisis y perspectivas", en: PÉREZ, Fernando; NÚÑEZ PAZ, Miguel; GARCÍA, Isabel (Coords.), Universitas Vitae. Homenaje a Ruperto Núñez Barbero, Salamanca: Ediciones Universidad de Salamanca, 2014, pp. 272-302, pp. 281 y ss. Sobre la discusión respecto a si la ONU tiene o no un concepto de terrorismo, ampliamente ABAD CASTELOS, Montserrat, "El concepto de terrorismo y los problemas relativos a su ausencia en el ámbito de las Naciones Unidas", en: CONDE, Elena (Dir.) e IGLESIAS, Sara (Coord.), Terrorismo y legalidad internacional, Madrid: Dykinson, 2012, pp. 105-126, 107-109. Afirmando que en ninguna instancia internacional se define lo que es terrorismo TORRES VÁSQUEZ, "El concepto de terrorismo", cit. nota n 6 , p. 90.
} 
VILLEGAS, Myrna. "Contribuciones para un concepto de terrorismo en el derecho penal chileno".

Algunos instrumentos lo consideran una estrategia que atenta o amenaza la integridad territorial y la seguridad de $\operatorname{los}$ Estados $^{13}$, otros aluden al terror o la intimidación como modus operandi, relegando a un segundo plano la finalidad política (identificada con amenazas para la seguridad de los Estados, obtener un objetivo o concesión política ${ }^{14}$ ) y otros, como la Estrategia Global de Naciones Unidas contra el terrorismo, lo refieren como un atentado contra el orden constitucional interno de un Estado y la democracia ${ }^{15}$.

La normativa regional tampoco es unánime en sus criterios. En Europa, fuente de inspiración de la actual reforma en Chile ${ }^{16}$, la Decisión Marco del Consejo sobre la lucha contra el terrorismo (2002/475/JAI) define al terrorismo en base a un elemento instrumental, esto es, la ejecución de conductas de cierta gravedad ${ }^{17}$ que puedan lesionar gravemente a un país o a una organización internacional, pero también otras menos graves $^{18}$. Un elemento teleológico, pues el autor debe actuar alternativamente con una finalidad intimidatoria, (intimidar gravemente a una población), coactiva (obligar indebidamente a los poderes públicos o a una organización internacional a realizar un acto o abstenerse de hacerlo) o desestabilizar gravemente o destruir las estructuras fundamentales políticas, constitucionales, económicas o sociales de un país o una organización internacional y por último, un elemento estructural, que se satisface con la pertenencia y dirección en organización terrorista.

El elemento subjetivo causó discrepancias al interior del Consejo. Algunas delegaciones solicitaron limitar la definición para que no pudiera abarcar a movimientos de oposición legítima (p.ej. sindicales o antiglobalización) ${ }^{19}$. Quienes se opusieron fueron España, Francia, Italia, Portugal y Grecia, grupo que poco a poco fue consolidando su predominio ${ }^{20}$. Actualmente la nueva estrategia antiterrorista europea alcanza también los movimientos antiglobalización ${ }^{21}$.

\footnotetext{
${ }^{13}$ ARES/49/60 de 9.12.1994, Convenio internacional para la represión de atentados terroristas cometidos con bombas (A/RES/52/164 de 15.12.1997), Convenio internacional para la represión de los actos de terrorismo nuclear (A/RES/59/290 de 13.04.2005), Convenio internacional para la represión de la financiación del terrorismo (A/RES/54/109 de 9.12.1999).

${ }_{14}$ Art. 2 Convenio internacional para la represión de la financiación del terrorismo (A/RES/54/109 de 9.12.1999).

${ }^{15} \mathrm{La} \mathrm{A} / \mathrm{RES} / 60 / 288$ de 20.09. 2006 declara que el terrorismo tiene por objeto "la destrucción de los derechos humanos, las libertades fundamentales y la democracia, amenazando la integridad territorial y la seguridad de los Estados y desestabilizando los gobiernos legítimamente constituidos...". También A/RES/52/164

${ }^{16}$ Mensaje Núm. 755-362 de 3.11.2014 mediante el cual se reforma la ley de conductas terroristas, el código penal y el código procesal penal e Informe de la Comisión de Expertos del Ministerio del Interior y la Seguridad Pública del Gobierno de Chile sobre la regulación jurídica de las conductas terroristas, de 13.10. 2014.

${ }^{17}$ Muertes, lesiones graves, secuestro, destrucciones significativas. Decisión Marco 2002/475/JAI del Consejo de Europa de 13.06.2002 sobre la lucha contra el terrorismo

${ }_{18}$ Por ejemplo, amenazas, pero también conductas periféricas: hurto, robo, chantaje y falsificación de documentos con el fin de cometer atentados terroristas, la provocación para cometer delitos de terrorismo, el reclutamiento y el adiestramiento. Estas tres últimas incorporadas por la Decisión Marco 2008/919/JAI del Consejo de Europa de 28.11.2008

${ }^{19}$ PÉREZ CEPEDA, "Definición del delito de terrorismo", cit. nota n 8, p. 62.

${ }^{20}$ GARCÍA RIVAS, "La tipificación "europea" del delito terrorista", cit. nota n 12, pp. 291 - 292.

${ }^{21}$ Lo anunciaba ya en 2009 FERNÁNDEZ REQUENA, Juan, El delito de terrorismo urbano o de baja intensidad. Análisis del artículo 577 CP, Valencia: Tirant Lo Blanch, 2009, p. 32.
} 
Polít. crim. Vol. 11, No 21 (Julio 2016), Art. 6, pp. 140-172.

[http://www.politicacriminal.cl/Vol_11/n_21/Vol11N21A6.pdf]

Por otra parte, la poca precisión técnica de la definición de terrorismo ha provocado una defectuosa y tardía transposición en las legislaciones internas ${ }^{22}$, habiéndose detectado fórmulas con conceptos indeterminados e incluso presunciones de finalidad terrorista, tal y como dan cuenta los informes de la Comisión Europea ${ }^{23}$.

En nuestra región, la Convención Interamericana contra el Terrorismo (Barbados, junio 2002), no define el terrorismo remitiéndose en su artículo 2 a las conductas señaladas en todos los instrumentos internacionales aprobados por Naciones Unidas hasta ese año. Así, el abanico de conductas terroristas se despliega ampliamente y no siempre está presente un elemento subjetivo relativo a la finalidad de los autores. Sin embargo, a diferencia de la normativa europea, destaca que el terrorismo tiene una finalidad política mucho más restrictiva, circunscrita a la protección de los respectivos órdenes constitucionales democráticos $^{24}$. A semejanza de ella parece considerar que el terrorismo es organizado ${ }^{25}$, pues obliga a los Estados a regular el financiamiento al terrorismo, el lavado de dinero, y mecanismos de cooperación policial y judicial en ámbitos transfronterizos.

\section{Elementos esenciales en el terrorismo según los instrumentos internacionales y restricciones del campo definitorio para un concepto jurídico.}

La indefinición de terrorismo a nivel internacional ha provocado una descentralización en su regulación jurídica al dejar en manos de cada Estado la potestad discrecional de decidir qué es terrorismo y qué no lo es, lo que ha traído como consecuencia un aumento de la inseguridad jurídica y la deslegitimación de la acción internacional en su contra, a causa de la politización del concepto ${ }^{26}$.

Por ello, y en un esfuerzo por encontrar comunes denominadores, podemos identificar los siguientes, que en algunas definiciones son copulativos y en otras no ${ }^{27}$ :

a) Es un acto político, en sentido amplio, pues pretende atentar contra la seguridad de los Estados (terrorismo internacional) o contra el orden constitucional de los Estados (terrorismo interno). La normativa europea agrega a las organizaciones internacionales como objeto de ataque (Decisión Marco 2002/746/JAI).

b) Finalidad intimidatoria (contra una población o a un sector de ella), la que se presenta en algunas definiciones como el modus operandi para alcanzar una finalidad

\footnotetext{
${ }^{22}$ PÉREZ CEPEDA, "Definición del delito de terrorismo", cit. nota ${ }^{\circ}$ 8, p. 61, nota 6 .

${ }^{23}$ Informes de la Comisión Europea 2004/688 de 8.06.2004 y 2007/1463 de 6.11.2007 sobre implementación de Decisión Marco.

${ }^{24}$ En su preámbulo expresa que el terrorismo "atenta contra la democracia, impide el goce de los derechos humanos y las libertades fundamentales, amenaza la seguridad de los Estados, desestabilizando y socavando las bases de la toda la sociedad...". Los Estados deben "promover y defender la democracia representativa". ${ }^{25}$ VILLEGAS DÍAZ, Myrna, "Convención Interamericana contra el terrorismo: Entre la involución de las garantías y la desprotección de los derechos humanos", Revista de Derecho y Humanidades, $\mathrm{N}^{\circ} 9$ (20022003), pp. 175-201, p. 178.

${ }^{26}$ VACAS FERNÁNDEZ, Félix, El terrorismo como crimen internacional, Valencia: Tirant Monografías 750, pp. 113-114, 123 y ss.

${ }^{27}$ Para una propuesta de elementos del terrorismo en el derecho internacional, ampliamente VACAS FERNÁNDEZ, El terrorismo como crimen internacional, cit. nota n ${ }^{\circ} 26$, pp. 141 y ss.
} 
VILLEGAS, Myrna. "Contribuciones para un concepto de terrorismo en el derecho penal chileno".

política (ONU). En otras definiciones aparece como fin inmediato de la actividad terrorista (normativa europea).

c) Finalidad coactiva (obligar a un gobierno u organización internacional para que haga o deje de hacer algo), la que se presenta alternativamente a la intimidación.

d) Debe tratarse de conductas de cierta gravedad: causar muerte o lesiones graves, o tratándose de ataque a la propiedad, debe causar un daño de grandes proporciones, en propiedades públicas o privadas que cumplen una función social (instalaciones de infraestructura) $^{28}$. Se exceptúa la normativa europea comunitaria que contempla actos de menor gravedad (amenazas, delitos de expresión, delitos "ligados" a la actividad terrorista).

e) En la mayoría de los instrumentos internacionales se alude a violaciones graves a los derechos fundamentales (a excepción de la normativa europea comunitaria)

f) En todas destaca el elemento organizacional, esto es, el terrorismo es llevado a cabo por organizaciones terroristas (excepto la normativa europea que contempla la posibilidad de terrorismo individual).

Es así como la idea de terrorismo en cuanto estrategia de dominación ${ }^{29}$ ha superado la noción de terrorismo como simple método de acción criminal $^{30}$, reconociéndolo como violencia política ilegítima sistemática, capaz de generar un efecto comunicativo en sus destinatarios mediante el recurso a la intimidación, para alcanzar fines políticos.

\section{Modelos de tratamiento jurídico penal del terrorismo.}

Sustantivo penalmente es posible identificar un primer nivel de análisis fundado en el carácter de la norma que contiene al terrorismo. Así, puede ser un delito común o un delito sui generis. Es posible además que pueda constituirse como una agravante genérica de responsabilidad penal.

Quienes estiman que debe tratarse como delitos comunes señalan que no es racional pedir al derecho interno que defina jurídicamente un concepto indeterminado a nivel internacional y en las ciencias sociales. Lo que empeora cuando se le asocia un tratamiento procesal agravatorio. Por el contrario, reconducir los delitos de terrorismo al régimen sustantivo penal y procesal comunes traería la ventaja de castigar por el delito de que se tratare con la aplicación de las agravantes que correspondiere, incluida la de uso de medios catastróficos, evitando así problemas concursales ${ }^{31}$.

\footnotetext{
${ }^{28}$ art. 2.1 del Convenio para la represión de atentados terroristas cometidos con bombas, y art. 2 del convenio para la represión de financiación al terrorismo, ambos ratificados por Chile

${ }_{29}$ REINARES, Fernando, "Características y formas del terrorismo político en las sociedades industriales avanzadas”, Revista Internacional de Sociología, ํㅜ 5, mayo-agosto (1993), pp. 35-67, pp. 42 y 47.

${ }^{30}$ Historia de la ley 19.027 de 24 de enero de 1991, Modifica la ley 18.314, p.5. En la idea también de terrorismo como método de los narcotraficantes RODRÍGUEZ SÁNCHEZ LARA, Gerardo; NIETO MUÑOZ, Judith, "El terrorismo como método del crimen organizado en México", en: BENÍTEZ, R., Crimen organizado e Iniciativa Mérida en las relaciones México-Estados Unidos, México: Colectivo de Análisis de la Seguridad con Democracia, CASEDE, 2010, pp. 87-95, p. 87.

${ }^{31}$ GUZMÁN DALBORA, "El terrorismo como delito común”, cit. nota nº 4, pp. 432, 474.
} 
Polít. crim. Vol. 11, No 21 (Julio 2016), Art. 6, pp. 140-172.

[http://www.politicacriminal.cl/Vol_11/n_21/Vol11N21A6.pdf]

Sin perjuicio de ser una postura respetable, no podemos soslayar un importante dato fáctico: el derecho penal del enemigo ha trasuntado a nuestra región, pero más que éste, que "parece recortado sobre el terrorista islámico" 32 y por ende es ajeno a nuestra realidad, lo que resulta preocupante es la importación de la lucha contra la criminalidad como concepto normativo (derecho penal de lucha), y especialmente, en la criminalidad terrorista. Ello porque al contener un mandato de control de la guerra para el Estado, provoca un cambio en las reglas de interpretación y aplicación del derecho, impidiendo que el juez sea un tercero imparcial ${ }^{33}$. Así las cosas, la norma se convierte en una fuente de legitimación de ese espacio de lucha donde pretende ganársele al terrorista, y pasa a servir a fines ajenos a ella misma.

En este escenario, pareciera que el tratamiento del terrorismo como un delito sui generis es inevitable, lo que también parece echar por tierra la posibilidad de convertirse en una agravante genérica, sin perjuicio de algunas excepciones ( $\mathrm{CP}$ argentino).

En el terrorismo como delito sui generis, podemos distinguir a su vez, un segundo nivel de análisis fundamentado en sus elementos y que se agrupa en tres grandes modelos: objetivo, subjetivo y objetivo-subjetivo.

\subsection{Modelo Objetivo.}

El modelo objetivo define el terrorismo a partir de la organización terrorista, considerando que ella "es el concepto dogmático nuclear, la base de toda la configuración de los tipos", pues "solo la organización está en condiciones de desplegar los medios típicos y de plantear la proyección estratégica exigida por la definición típica"34.

Este modelo es asumido por el §129a StGB alemán, que ubicando el terrorismo dentro de los delitos contra el orden público, considera como elemento central la formación y/o pertenencia a una organización terrorista. A partir de este elemento estructural, que se yergue como tipo penal autónomo, se desprende el resto en cascada (conductas y eventual elemento subjetivo) para proceder a la calificación como terrorista de ciertas infracciones.

La organización terrorista se define según dos criterios: las formas de comisión, y el teleológico ${ }^{35}$. La organización será terrorista cuando persigue la comisión de determinados delitos: asesinato u homicidio, genocidio, crímenes de guerra, delitos contra la libertad personal (secuestro extorsivo y toma de rehenes), causar daños físicos o mentales graves a un ser humano mediante violencias, incendios graves, destrucción de edificios, delitos contra el medio ambiente y algunas infracciones de la ley de control de armas, entre otros.

\footnotetext{
${ }^{32}$ DONINI, Massimo, "Derecho penal de lucha. Lo que el debate sobre el derecho penal del enemigo no debe limitarse a exorcizar”, en: CANCIO, Manuel; POZUELO, Laura (Coords.), Política criminal en vanguardia. Inmigración clandestina, terrorismo, criminalidad organizada, Madrid: Thompson Civitas, 2008, pp. 29-75, p. 47.

${ }^{33}$ DONINI, "Derecho penal de lucha", cit. nota n 32, pp. 35, 67 y 68.

${ }^{34}$ CANCIO MELIÁ, Manuel, Los delitos de terrorismo: estructura típica e injusto, Madrid: Reus, 2010, p. 261.

${ }^{35}$ AMBOS, Kai, El derecho penal frente a amenazas extremas, Madrid: Dykinson, 2007, p. 43.
} 
VILLEGAS, Myrna. "Contribuciones para un concepto de terrorismo en el derecho penal chileno".

A la circunstancia de cometer los delitos perteneciendo a una organización, y tratándose de ciertos delitos graves $^{36}$, se añade la de que el sujeto tiene que haber actuado con la finalidad de intimidar a la población, obligar indebidamente y mediante la fuerza o amenaza de ella a una autoridad pública u organización internacional, o de destruir las estructuras políticas, constitucionales, económicas o sociales de un país o de una organización internacional o para dañar o afectar de manera significativa a un Estado u organización internacional ${ }^{37}$.

En suma, para el derecho penal alemán, comete delitos de terrorismo: a) quien forma o pertenece a una asociación terrorista, b) quien comete los delitos ya especificados (que son delitos comunes) perteneciendo a dicha organización, y c) en delitos más graves además debe presentarse como elemento subjetivo en el tipo, la finalidad intimidatoria o coactiva en el agente. El StGB no considera el terrorismo individual y permite perseguir a organizaciones terroristas en el extranjero conforme a su normativa cuando sus miembros se encuentren en territorio alemán ${ }^{38}$. Lo central en este modelo es la concepción de delito de organización, que se define por la dimensión colectiva de la organización ilícita, la significación pública de su existencia ${ }^{39}$, el potencial humano y técnico disponible para la realización de delitos, una organización externa que hace posible una voluntad común, una finalidad criminal sistémicamente constitutiva, y la disposición interna de adhesión a la organización por parte de sus miembros ${ }^{40}$.

Sin perjuicio de la teoría que se adopte para la fundamentación del injusto en los delitos de organización en general $^{41}$, respecto del terrorismo quien la ha desarrollado con profundidad es Cancio manifestando que se trata de "una estructura organizativa que se proyecta más allá de la comisión de unos hechos concretos"42. La plantea como un sistema de injusto constituido, cuya dimensión específica reside en la arrogación del monopolio estatal de la violencia. La especificidad de la organización terrorista está en su estrategia de comunicación en el sentido de pretender "desafiar" al poder del Estado, radicando allí su peligrosidad más allá del ataque a bienes jurídicos individuales específicos ${ }^{43}$. Una especie de ser vivo, en donde el sujeto pierde el control de la misma, quedando supeditado a la estructura. La integración en el colectivo comportaría un desplazamiento de la esfera privada, en el sentido de poder serle imputable al sujeto que pertenece a ella,

\footnotetext{
${ }^{36}$ Infligir graves daños físicos o mentales a una persona, delitos catastróficos (incendios graves, destrucción de propiedades), delitos contra el medio ambiente, ley de control de armas, entre otros.

37 Este elemento subjetivo fue incluido mediante la Ley (BGBI. I S. 2836) MWV 28.12.2003 sobre la aplicación de la Decisión Marco (2002/746/JAI) cit. nota $\mathrm{n}^{\circ} 17$.

${ }^{38}$ AMBOS, El derecho penal, cit. nota ${ }^{\circ} 35$, p. 43.

39 CANCIO MELIÁ, Manuel y SILVA SÁNCHEZ, Jesús, Delitos de organización, Montevideo-Buenos Aires: BdF, 2008, p. 34; CANCIO MELIÁ, Los delitos de terrorismo, cit. nota n 34, p. 99.

${ }^{40}$ MAÑALICH RAFFO, Juan Pablo, "Organización delictiva. Bases para su elaboración dogmática en el derecho penal chileno”, Revista Chilena de Derecho, Vol. 38, N² (2011), pp. 279-310, p. 281.

${ }^{41}$ Teoría del abuso del derecho de asociación, teoría de la anticipación, teoría del bien jurídico colectivo paz pública o seguridad interior, teoría del injusto como amenaza (Jakobs). Ampliamente CANCIO/SILVA, Delitos de organización, cit. nota $\mathrm{n}^{\circ} 39$, pp. 35 y ss.

${ }^{42}$ CANCIO MELIÁ, Manuel, "El delito de pertenencia a una organización terrorista en el Código Penal Español”, en: LUZÓN PEÑA, Diego (Dir.), Derecho Penal del Estado Social y Democrático de Derecho. Libro Homenaje a Santiago Mir Puig, Madrid: La Ley, 2010, pp. 987-1010, p. 992.

${ }^{43}$ CANCIO MELIÁ, Los delitos de terrorismo, cit. nota n ${ }^{\circ} 34$, pp. 126 y ss. Cfr. GUZMÁN DALBORA, José Luis, Estudios y Defensas Penales, Santiago de Chile: Legal Publishing, 2009, pp.146-147.
} 
Polít. crim. Vol. 11, No 21 (Julio 2016), Art. 6, pp. 140-172.

[http://www.politicacriminal.cl/Vol_11/n_21/Vol11N21A6.pdf]

comportamientos que, si no estuviera integrado en ella, no pasarían tal vez de ser actos preparatorios. No se requiere por tanto, ningún elemento subjetivo relativo a la finalidad ${ }^{44}$.

Un modelo similar es el chileno sostenido en el Anteproyecto de Código Penal de diciembre de 2013, y en el Informe de la Comisión de Expertos de 2014, que proponen regular el terrorismo a partir de la asociación terrorista como hecho punible autónomo, y diferenciando la pena para sus integrantes según fueren miembros o directivos. La principal diferencia estriba en que en el Anteproyecto, la asociación ilícita común y la terrorista se regulan en párrafos distintos, esta última, en un párrafo expresamente destinado al terrorismo, junto con el tipo penal de financiamiento y otras consideraciones penológicas, mientras que en la propuesta de la Comisión, habría una sola regulación, la asociación criminal, y un tipo de ella, sería la terrorista. En esta última, la lesividad proviene de la lesividad genérica, propia de toda asociación ilícita, y de la lesividad específica que le otorga su carácter terrorista ${ }^{45}$. La calificación terrorista procede entonces respecto de la organización, y los delitos que se cometen por sus integrantes son delitos comunes, calificables de crímenes en el sentido del art. 3 del CP.

Otra diferencia es la regulación de la asociación ilícita común, que en la propuesta del Anteproyecto asume la forma clásica de organización vertical y jerarquizada, y señala explícitamente la cantidad de miembros ${ }^{46}$, lo que no sucede en la propuesta de la Comisión de Expertos.

En la propuesta del Anteproyecto de CP, la asociación criminal terrorista queda integrada por tres elementos: a) el uso de medios catastróficos y/o armas de fuego, b) la finalidad política de subvertir o alterar gravemente el sistema constitucional, económico o social del Estado, siendo la producción de temor en la población o la imposición de condiciones a la autoridad un medio en la conducta del agente para alcanzarla, y c) la comisión de determinados delitos comunes: homicidios, lesiones graves, privaciones de libertad, sustracción de menores, incendios, estragos u otros atentados contra la propiedad o infraestructura pública o privada.

Esta formulación presenta varias ventajas. La principal es otorgar a los medios la relevancia que merecen en el tipo penal, y especificarlos. Otra ventaja es que reconoce la finalidad política en el terrorismo y a la vez evita la psicologización del concepto al otorgar a la producción de temor el carácter de medio en la conducta, siendo en este sentido también aceptable que se contemple la imposición de condiciones a la autoridad ya que ellas no aparecen desvinculadas de la finalidad política, sino un medio para alcanzarla. Y por último, entiende que los delitos de terrorismo son delitos graves, razón por la cual los especificados en el tipo penal son de esa naturaleza. Con esto muestra las características centrales del terrorismo.

\footnotetext{
${ }^{44}$ CANCIO MELIÁ, Los delitos de terrorismo, cit. nota ${ }^{\circ}$ 34, p. 124.

${ }^{45}$ Informe de la Comisión de Expertos de 2014, cit. nota ${ }^{\circ} 16$, p. 16.

${ }^{46}$ Señala en su art. 583 inciso 2 "Es asociación delictiva toda organización jerarquizada compuesta por tres o más personas que tiene por fin o actividad permanente la comisión de delitos”.
} 
VILLEGAS, Myrna. "Contribuciones para un concepto de terrorismo en el derecho penal chileno".

La primera desventaja que presenta, es que se castiga no solo la dirección sino la mera integración en la asociación ilícita, al margen de un hecho delictivo concreto, supuesto que tiene un injusto que se satisface a sí mismo. La segunda, es un problema de interpretación respecto de delitos que pudieren cometerse en contra de la propiedad, pues de la redacción no queda claro que los incendios, estragos y otros atentados que se cometan en propiedad privada, lo sean en aquella que prestare alguna función social (según el Convenio Internacional para la represión de atentados terroristas cometidos con bombas).

En la propuesta de la Comisión de Expertos se modifica el decimonónico tipo penal de asociación ilícita (art. 292 del CP), en los siguientes términos: a) la asociación es punible en forma autónoma cuando tiene por finalidad la perpetración de crímenes, b) debe encontrarse efectivamente organizada, lo que se constataría a través de: la cantidad de miembros, su dotación de recursos y medios, y su capacidad de planificación e incidencia sostenida en el tiempo. Esta organización muta en organización terrorista cuando a través de la comisión de ciertos delitos comunes persigue alternativamente una finalidad política, coactiva o psicológica.

La formulación presenta también algunas ventajas, como por ejemplo, que la reformulación del tipo penal de asociación ilícita común permite incluir otras formas de organización que no cuenten a su haber con el requisito de la verticalidad, aun cuando esta misma ventaja pudiera traer consigo otras consecuencias no deseables al ser puesta en práctica, como extender la punición hacia otras formas de delincuencia. Lo mismo sucede al dejar en manos del juez la responsabilidad de decidir cuándo ella se constituye pues no señala ningún parámetro en relación a la cantidad de miembros necesarios para conformar una organización, ni tampoco en relación a los medios que debe utilizar. No se trata de fijar un número de miembros, sino al menos evitar la colisión con la conspiración y la proposición para delinquir. Respecto de los medios, al quedar éstos abiertos, sin especificación respecto de la asociación terrorista, podría llevar a considerar terroristas una serie de lesiones u homicidios cometidos a través de medios inocuos para causar terror en la población (objetos cortantes, punzantes o contundentes), lo que implica una contradicción con una de las características centrales en el terrorismo, y que por lo demás, está explicitada en la misma norma como una de las finalidades alternativas.

Respecto de las finalidades exigidas, es correcta la exigencia de un elemento subjetivo político (socavar el orden constitucional democrático), porque ello refleja la protección al objeto de tutela penal -sin perjuicio de que la construcción dogmática de la propuesta prescinde en su formulación del bien jurídico- pero no lo parece la forma en la que están construidas las otras dos finalidades, pues son alternativas a la política. La finalidad coactiva (arrancar decisiones a la autoridad o imponerle exigencias), podría abrir en forma desmesurada el tipo penal, considerando especialmente que los delitos que la asociación debe cometer, no son todos a través de medios catastróficos. Respecto de la finalidad de "someter o desmoralizar a la población infundiendo temor generalizado", no logra salvar el escollo a que hace alusión la misma propuesta en cuanto a la "psicologización" del concepto de terrorismo en su actual formulación, pues ahora la carga de la prueba se trasladaría desde el fuero interno del sujeto (caso de la actual ley) a comprobar a un 
Polít. crim. Vol. 11, No 21 (Julio 2016), Art. 6, pp. 140-172.

[http://www.politicacriminal.cl/Vol_11/n_21/Vol11N21A6.pdf]

"resultado" de desmoralización en la población. La fórmula "someter a través del miedo" quedaría mejor si se hiciera una adecuada combinación con los medios.

Con todo, resulta acertada la propuesta en cuanto a la delimitación de las figuras comunes: apremios ilegítimos por parte de funcionarios públicos, algunos delitos contra la salud pública, diseminación de gérmenes patógenos. Respecto de los homicidios, las mutilaciones y las lesiones, la combinación de la conducta más el elemento subjetivo, especialmente si consideramos que las finalidades se exigen en forma "alternativa", puede llevar a ampliar la punibilidad al momento de aplicar la norma. Respecto del nuevo tipo penal que la Comisión propone art. 403 ter que castiga conductas relacionadas con artefactos explosivos, parece que debería desaparecer habida consideración de su inclusión en la Ley $\mathrm{N}^{\circ} 17.798$ mediante reforma de la Ley $\mathrm{N}^{\circ} 20.813$ de 6 de febrero de 2015, o bien arriesgarse a un concurso aparente, no siempre fácil, de resolver. El ejemplo quedaría de manifiesto en el caso de grupos de encapuchados que pretendiendo arrancar decisiones a la autoridad en materia de educación, en forma sistemática arrojaran artefactos explosivos en la vía pública.

Así las cosas, cabría preguntarse qué tan pertinente es intentar implementar en nuestra legislación, el modelo de delitos de organización respecto del terrorismo. Consciente de ir en contra de una corriente de pensamiento que va en franca expansión en Europa y al parecer en nuestro país, parece necesario examinar el problema de la organización terrorista desde una perspectiva fenoménica, y por ende criminológica y político criminal, a fin de que la dogmática jurídico penal no se convierta en una herramienta dúctil para cualquier poder político.

\subsubsection{Cuestionamiento a las bases criminológicas del terrorismo como delito de organización.}

La idea de que la organización terrorista debe constituir un injusto en sí misma parte de la base de que el terrorismo es una forma de crimen organizado ${ }^{47}$. De ahí que la tendencia en Europa sea la de elaborar un arsenal jurídico para hacerle frente, con normas sustantivo penales y procesal penales idénticas para todo el crimen organizado. Pero ¿Qué define a este último? ¿Sólo el elemento objetivo de una organización para perpetrar sus delitos?

El concepto de crimen organizado, al igual que el de terrorismo, tampoco es unívoco ${ }^{48}$, no obstante la Convención de las Naciones Unidas contra la Delincuencia Organizada Transnacional (A/RES/55/25 de 15.11.2000)y sus protocolos (Nueva York, 2004), en adelante Convención de Palermo, si bien no lo define explícitamente, sí establece copulativamente sus elementos: se estructura a través de una organización ("grupo delictivo organizado"), que actúa con el propósito de cometer delitos graves definidos en la misma

\footnotetext{
${ }^{47}$ Por todos, CANCIO MELIÁ, Los delitos de terrorismo, cit. nota ${ }^{\circ} 34$, p. 89.

${ }^{48}$ Lo decía ya QUINTERO OLIVARES, Gonzalo, "La criminalidad organizada y la función del delito de asociación ilícita”, en: FERRÉ, Juan Carlos y ANARTE, Enrique (Eds.), Delincuencia organizada. Aspectos penales, procesales, y criminológicos, Huelva: Publicaciones Universidad de Huelva, 1999, pp. 177-190, p.177. Lo sigue sosteniendo GONZÁLEZ CUSSAC, José Luis, “Tecnocrimen” en: GONZÁLEZ, José Luis; CUERDA, María Luisa (Dirs.), FERNÁNDEZ, Antonio (Coord.), Nuevas amenazas a la seguridad nacional. Terrorismo, criminalidad organizada y tecnologías de la información y la comunicación, Valencia: Tirant Lo Blanch, Monografías 833, 2013, pp. 205-241, pp. 209 y ss.
} 
VILLEGAS, Myrna. "Contribuciones para un concepto de terrorismo en el derecho penal chileno".

convención, y con la finalidad de obtener directa o indirectamente "un beneficio económico u otro beneficio de orden material" (art. 2). Además requiere el elemento transnacionalidad. En su preámbulo reconoce "los crecientes vínculos entre la delincuencia organizada transnacional y los delitos de terrorismo", es decir, separa ambas formas de criminalidad. En el mismo sentido se ha pronunciado el Congreso de los Estados Unidos ${ }^{49}$.

En contraste con lo anterior, en Europa se ha tomado una decisión político criminal de considerar al terrorismo como una forma de crimen organizado, que en el caso español, se concreta incluso normativamente ${ }^{50}$, lo que trajo como consecuencia que la dimensión normativa de la organización terrorista se asemeje bastante a la Convención de Palermo.

En mi opinión, terrorismo y crimen organizado son cosas diferentes ${ }^{51}$, sin perjuicio de las relaciones que pudieran existir entre ellos. Entre ambos se aprecian a lo menos dos grandes diferencias: teleológica y operacional ${ }^{52}$.

Una diferencia teleológica pues el terrorismo tiene una finalidad política, el crimen organizado, tiene una finalidad lucrativa ${ }^{53}$. El hecho de que el terrorismo necesite de un entramado financiero para poder funcionar, no le otorga per se la categoría de crimen organizado, más bien el entramado financiero es uno de los medios a través de los cuales la actividad terrorista puede desarrollarse. El terrorismo tiene su propia especificidad, su finalidad es (a nivel interno) la alteración del orden constitucional democrático sea para destruirlo y sustituirlo (terrorismo insurgente), o como instrumento complementario de las políticas gubernamentales de control social (terrorismo de agentes estatales) ${ }^{54}$.

Derivado de lo anterior, el terrorismo cuestiona abiertamente la autoridad del Estado, y con ello se pone "fuera" del Estado, en cambio, el crimen organizado actúa "dentro" del Estado, pareciendo incluso abrazar los principios del Estado de Derecho, desde que busca, una vez conseguida su finalidad lucrativa, el "lavar" su procedencia ilícita o al menos darle apariencia de legalidad. El acto mismo de blanqueo, desde que pretende que los activos le pertenezcan "legalmente", implica hacer suyos los fundamentos de una democracia liberal $^{55}$.

\footnotetext{
${ }^{49}$ FINKLEA, Kristin, "Organized Crime in the United States: Trends and Issues for Congress", Documentos de investigación del Congreso de los EE.UU, 2010, en: http://www.fas.org/sgp/crs/misc/R40525.pdf, pp. 24 y ss. [visitado el 10.06.2015].

${ }^{50}$ Art. 282 bis.4 Ley de Enjuiciamiento Criminal.

${ }^{51}$ En esta misma opinión QUINTERO OLIVARES, "La criminalidad organizada", cit. nota ${ }^{\circ}$ 48, p. 178, ZÚÑIGA RODRÍGUEZ, Laura, "Criminalidad de empresa, criminalidad organizada y modelos de imputación penal”, en: FERRÉ, Juan Carlos y ANARTE, Enrique (Eds.), Delincuencia organizada. Aspectos penales, procesales y criminológicos, Huelva: Publicaciones Universidad de Huelva, 1999, pp. 199-235, p. 200.

52 Ampliamente VILLEGAS DÍAZ, Myrna, “Terrorismo: ¿Crimen Organizado? Análisis comparado”, Anales de la Facultad de Derecho, Universidad de Chile, 2004, pp. 227-248, pp.235-240.

${ }^{53}$ VILLEGAS DÍAZ, “Terrorismo: ¿Crimen organizado?”, cit. nota n ${ }^{\circ} 52$, p. 235.

${ }^{54}$ VILLEGAS DÍAZ, Myrna, "Los delitos de terrorismo en el Anteproyecto de Código Penal", Revista Política Criminal, $\mathrm{N}^{\circ}$ 2, A3 (2006), pp. 1-31, p. 7.

${ }^{55}$ VAN DIJCK, Maarten, "Discussing Definitions of Organized Crime: Word Play in Academic and Political Discourse”, Humsec Journal, Issue 1 (2007), pp. 65-90, p. 82. En un estudio empírico reciente en Chile se arroja como resultado algo similar, el narcotraficante chileno puede operar bajo un manto de licitud para
} 
Polít. crim. Vol. 11, No 21 (Julio 2016), Art. 6, pp. 140-172.

[http://www.politicacriminal.cl/Vol_11/n_21/Vol11N21A6.pdf]

La segunda diferencia que puede observarse con el crimen organizado es de carácter operacional. El terrorismo busca la publicidad de sus actos, busca comunicar un mensaje, para poder destruir voluntades, mientras que el crimen organizado, busca, en general, el ocultamiento de los mismos ${ }^{56}$. Ello sin perjuicio de las excepciones que pudieran presentar en relación al primero, el terrorismo de estado y respecto del segundo, el gran narcotráfico.

Es tan asumida esta diferencia entre terrorismo y crimen organizado en América Latina que las legislaciones los consideran fenómenos distintos. Por eso el mandato contenido en el art. 6 de la Convención Interamericana contra el Terrorismo (2002), que ordena a los Estados equiparar el terrorismo a los delitos determinantes del lavado de dinero ${ }^{57}$, ha ocasionado no pocas dificultades. Cuando se buscan las conexiones entre terrorismo y crimen organizado, se alude a que este último usa "métodos terroristas".

No deja de ser incomprensible esta vis atractiva del crimen organizado hacia el terrorismo. Probablemente porque en un Estado constitucional de derecho, es menos polémico justificar regímenes penales y procesales restrictivos de garantías respecto del crimen organizado, no así de un fenómeno cuyos deslindes con la violencia emancipatoria y los movimientos de liberación nacional todavía no son claros. Y de ahí esta tendencia a llevar el terrorismo hacia el crimen organizado (como han hecho los europeos), en circunstancias que podría ser a la inversa, esto es, atraer cierto tipo de crimen organizado al terrorismo.

Tanto en México como en Colombia, grandes carteles de droga han alcanzado un poder tal que dominan política, militar, económica y socialmente zonas geográficas enteras, debilitando a la autoridad política local elegida democráticamente, o bien la cooptan mediante actos de corrupción. Se convierten en verdaderos actores políticos y sociales en un territorio determinado capaces de incidir en la toma de decisiones ${ }^{58}$, conformados como una especie de microestado, un poder paralelo al oficial.

Siendo así, y en la medida en que utilizan la violencia como "medio de modificación de las relaciones de poder" (político, económico o social) y el terror como forma de comunicar un mensaje ya sea al Estado, o a los habitantes de esa y otras localidades en particular, es posible pensar que pudieran sus actos calificarse como delitos de terrorismo ${ }^{59}$.

esquivar el control. SALINERO, Sebastián. "El crimen organizado en Chile. Una aproximación criminológica al perfil del delincuente a través de un estudio a una muestra no representativa de condenados por delitos de tráfico de estupefacientes", Revista Política criminal, Vol. 10, No 19 (Julio 2015), Art. 2, pp. 25-55, p. 48.

${ }^{56}$ Así lo han sostenido CASTILLO BARRANTES Enrique et. Al., "Criminalidad Organizada. Informe General de la Sociedad Internacional de Criminología", Trad. GERMÁN, Isabel, Cuadernos de Política Criminal, n 50 (1990), pp. 493-512, pp. 494 y 496, VILLEGAS DÍAZ, “Terrorismo: ¿Crimen organizado?”, cit. nota $\mathrm{n}^{\circ} 52$, pp. 237 y ss.

${ }^{57}$ VILLEGAS DÍAZ, "Convención Interamericana" cit. nota nº 25, p. 181.

${ }_{58}^{58}$ RODRÍGUEZ/NIETO, "El terrorismo como método", cit. nota n⿳ 30 , p. 89.

${ }^{59}$ En esta opinión, TERRADILLOS BASOCO, "El Estado de derecho", cit. nota $n^{\circ} 5$, p. 279. Cfr. VAN DIJCK, "Discussing", cit. nota $n^{\circ} 55$, p. 82, nota 56 , para quien el alcanzar poder político por parte de la mafia, tiene un objetivo económico subyacente o en último término de beneficio personal. Subraya que no es lo mismo crimen perpetrado por medios políticos que crimen político. 
VILLEGAS, Myrna. “Contribuciones para un concepto de terrorismo en el derecho penal chileno".

3.1.2. Cuestionamiento a los lineamientos político criminales del terrorismo como delito de organización.

El terrorismo históricamente ha tenido un componente político inserto ${ }^{60}$ que no puede obviarse, especialmente frente al riesgo de manipulación de las normas antiterroristas por parte de los Estados para aplacar a las disidencias. El modelo de delitos de organización aplicado al terrorismo tiene como base la punición de la pertenencia a la asociación terrorista, a partir de la cual se desprenden en cascada los delitos concretos de la actividad terrorista, que son a su vez, delitos comunes, y es esta posibilidad, la de castigar por la sola pertenencia, la que - en mi opinión- puede traer consigo en la criminalización secundaria, una politización de la norma indefendible desde el Estado constitucional de derecho.

El delito de asociación, en general, y en especial cuando se trata de la criminalidad terrorista, es "un delito procesal sirviente",61, pues cumple la función de anticipar una serie de intervenciones procesales antes de que se produzca la prueba de la comisión de uno de los concretos delitos fines de la organización, por ejemplo, interceptación de comunicaciones, detenciones, interrogatorios, uso de agentes encubiertos y provocadores, registros domiciliarios, etc. Sirve para probar "otros delitos ignotos a través de autores notorios",62, asegurando el control penal respecto de estos últimos, pasando entonces a ser irrelevante que se pruebe o no en el juicio que efectivamente cometieron el delitos ${ }^{63}$.

Basar la punición exclusivamente en la pertenencia a una organización criminal, al margen de un hecho delictivo concreto, ha sido impugnado desde posturas tan disímiles como las de Ferrajoli y Jesús Silva. Ferrajoli, desde el garantismo, afirma que ello atenta contra los límites al estado de derecho que imponen los principios de necesidad y lesividad ${ }^{64}$. En sintonía con él, Quintero Olivares ${ }^{65}$, añade que esto es especialmente notorio si se consideran las diferencias interpretativas que pueden plantearse entre la asociación ilícita y

\footnotetext{
${ }^{60}$ Estaba emparentado con los delitos de lesa majestad. Ampliamente GUZMÁN DALBORA, "El terrorismo como delito común", cit. nota n 4 , pp. 402-405.

${ }^{61}$ DONINI, "Derecho penal de lucha", cit. nota n ${ }^{\circ} 32$, p. 39.

${ }^{62}$ DONINI, "Derecho penal de lucha", cit. nota $n^{\circ}$ 32, p. 39. En similar sentido SILVA SÁNCHEZ, Jesús, "La intervención a través de organización ¿Una forma moderna de participación en el delito?”, en: CANCIO MELIÁ, Manuel y SILVA SÁNCHEZ, Jesús. Delitos de organización, Montevideo: Bs Aires, BdF, 2008, pp. 87-134, p. 91.

${ }^{63}$ Así por ejemplo, en el denominado Caso Bombas, $3^{\circ}$ Tribunal Oral en Lo Penal de Santiago, 13 de julio de 2012, R.U.C. No 0700277303-6, vs. Gustavo Fuentes y otros, que permitió el control de grupos okupas y anarquistas, que dio lugar a nuevos juicios que culminaron con la absolución de los imputados. Ver Tribunal Oral en Lo Penal de Puente Alto, 15 de junio 2014, RUC 1300145684-3, vs. Víctor Hugo Montoya. En el caso mapuche, el werken de la Coordinadora Arauco Malleco, H. Llaitul, fue procesado en 2001 por una ocupación territorial de la Hacienda Lleu Lleu, resultando heridos dos funcionarios policiales, lo que fue calificado como infracción a la Ley de Seguridad del Estado y sustanciado paralelamente ante la justicia ordinaria y la justicia militar (Corte de Apelaciones de Concepción, 13 de diciembre de 2001, rol 1-2001, vs. Héctor Llaitul y otros y $2^{\mathrm{a}}$ Fiscalía Militar de Concepción, rol ํㅜ 30-2001, vs. Héctor Llaitul. Más tarde fue condenado en el denominado Caso del atentado al fiscal, pero por un delito común (robo con intimidación) cuya investigación se sustanció conjuntamente con los otros delitos, conforme al procedimiento de la ley de conductas terroristas, Corte Suprema, 3 de junio de 2011, Rol 2921-2011, vs. Héctor Llaitul y otros.

${ }^{64}$ FERRAJOLI, Luigi, Derecho y Razón. Teoría del garantismo penal, Trad.: IBÀÑEZ, Perfecto; TERRADILLOS, José et. al, Madrid: Trotta, 1995, pp. 464 y ss.

${ }^{65}$ QUINTERO OLIVARES, “La criminalidad organizada", cit. nota no 48 , pp. 182 y ss.
} 
Polít. crim. Vol. 11, No 21 (Julio 2016), Art. 6, pp. 140-172.

[http://www.politicacriminal.cl/Vol_11/n_21/Vol11N21A6.pdf]

los actos preparatorios, pues en todo caso, de ser necesario el castigo a fases anteriores del delito, existe la fórmula de la tipificación expresa.

Jesús Silva ${ }^{66}$ por su parte, desde el expansionismo, sostiene la inconveniencia de punir la asociación ilícita desvinculada de un hecho concreto, e indica que la responsabilidad de los miembros de la asociación se fundamenta en la medida en que es posible imputarles la creación de riesgos para los bienes jurídicos protegidos que importan los delitos-fines de la organización criminal (teoría de la anticipación). Esto permite a su vez alejarse del derecho penal de excepción y tratar la atribución de responsabilidad penal de conformidad con las reglas comunes de imputación ${ }^{67}$.

La experiencia comparada muestra el peligro de criminalización de movimientos y partidos políticos, particularmente el caso español, donde existe una especie de "asociación ilícita sobrevenida" "68 , esto es, una organización legal que deviene en ilegal, como sucedió con la criminalización e ilegalización de la izquierda abertzale ${ }^{69}$. No deja de ser incomprensible el castigo de los que se agrupan (en la organización A, legal) para decidir agruparse (en la organización B ilegal) para luego delinquir. En Chile quiso emularse esta situación en la acusación contra la organización mapuche Coordinadora Arauco Malleco (CAM), donde se sostuvo que era una asociación ilícita terrorista. El tribunal, en su segunda sentencia, señaló que no había indicios de que existiera una asociación terrorista aparte y distinta de la CAM, cuyos fines eran lícitos al estar enmarcados dentro de lo que indica la Ley $\mathrm{N}^{\circ} 19.253$, y que si bien es cierto, se habían cometido delitos, estos respondían más bien a los caracteres de delitos cometidos por un grupo, pero no conformado como asociación ilícita ${ }^{70}$.

Otra desventaja del modelo de delito de organización en relación al principio democrático, es que su degeneración puede llevar a considerar como terrorista no solo al que pertenece, sino también a quienes la promueven, o incluso a "quienes desarrollan planteamientos político-institucionales que dan el ser y sentido a todo el grupo" "71, es decir, a quienes pertenecieron y dejaron de pertenecer. Con ello se pone en juego también el principio de resocialización.

El mero hecho de asociarse, integrar una organización terrorista que tiene un programa delictivo, supone un peligro para el ordenamiento constitucional democrático, sí y solo sí, existen indicios de que ha comenzado a ponerse en marcha el programa político destinado a

\footnotetext{
${ }^{66}$ SILVA SÁNCHEZ, “La intervención”, cit. nota n 62, pp. 98-100. En nuestro país, acogiendo la teoría de la anticipación respecto del terrorismo como delito de organización CARNEVALI RODRÍGUEZ, Raúl, "El Derecho Penal Frente al Terrorismo. Hacia un modelo Punitivo Particular y Sobre el Tratamiento de la Tortura", Revista de Derecho de la P. Universidad Católica de Valparaíso, Vol. XXXV (2 sem.2010), pp. 109-145, p. 122.

${ }^{67}$ SILVA SÁNCHEZ, “La intervención”, cit. nota n 62, pp. 87-134, p. 100.

${ }_{68}^{68}$ QUINTERO OLIVARES, “La criminalidad organizada”, cit. nota ${ }^{\circ} 48$, pp.184-185.

69 Ampliamente, MIRA BENAVENT, Javier, "El derecho penal ante el fin de ETA: la cuestión de la criminalización de su entorno político e ideológico", Hermes. Pentsamendu Eta Historia Aldizkaria, $\mathrm{N}^{\circ} 45$ (2013), pp. 4-14, pp. 6 y ss.

${ }^{70}$ Ministerio Público vs. Patricia Troncoso y otros (2005).

${ }^{71}$ MIRA BENAVENT, "El derecho penal ante el fin de ETA", cit. nota ${ }^{\circ}$ 69, p. 6.
} 
VILLEGAS, Myrna. "Contribuciones para un concepto de terrorismo en el derecho penal chileno".

atentar contra este bien jurídico ${ }^{72}$. Caso en que cabe castigar por esos actos delictivos concretos, debiendo operar la organización, o bien como un elemento del tipo, o bien como una condición objetiva de punibilidad.

\subsection{Modelo Subjetivo.}

El modelo subjetivo define el terrorismo con referencia a la presencia de una determinada finalidad que debe estar presente en el sujeto al momento de cometer la conducta. Tal finalidad puede ser: política, y causar terror o intimidación (sea como finalidad del sujeto o como resultado de la actividad terrorista), y/o coactiva (obligar al Estado u organismo internacional, o a la autoridad a hacer o dejar de hacer algo). Ellas pueden aparecer alternativa o conjuntamente en los tipos penales.

\subsubsection{Finalidad política.}

La finalidad política destaca al terrorismo como atentado contra el orden constitucional democrático. Puede estar referida a la realización del acto en sí, o a las finalidades de la organización terrorista. En América Latina recogen definiciones de terrorismo de esta índole el art. 391 del CP guatemalteco ("comete delito de terrorismo quien con la finalidad de alterar el orden constitucional, el orden público o coaccionar....") y el art. 133 del CP boliviano ("el que formare parte, actuare al servicio o colabore... con una organización armada....con la finalidad de subvertir el orden constitucional, deponer al gobierno elegido constitucionalmente...). En Europa son bastante más comunes ej: CP español (art. 573) que refiere la finalidad política al acto. El CP italiano (art. 270) que refiere la finalidad política a la organización (las que persiguen fines de terrorismo internacional o la subversión del orden constitucional).

Parece mucho más acotado a un bien jurídico determinado y determinable, el aludir a la alteración del orden constitucional, que al indeterminado concepto de alteración de la paz pública. Por otra parte, considerar terrorista a quienes atenten contra la integridad nacional, implica de suyo que los movimientos separatistas o incluso los de liberación nacional sean entendidos como terroristas, lo que es incompatible con los principios del estado constitucional de derecho ${ }^{73}$.

El problema de la inclusión de esta finalidad en un tipo penal, es que si se la desvincula de otro elemento esencial del terrorismo como es el causar temor, se corre el riesgo de calificar como terroristas situaciones de conflicto armado no internacional, dificultando la aplicación del derecho internacional humanitario. Pues los Estados muestran resistencia a catalogar como conflicto armado esta clase de escenarios, a fin de aplicarles su legislación interna ${ }^{74}$.

\footnotetext{
${ }^{72}$ VILLEGAS DÍAZ, "Los delitos de terrorismo", cit. nota n ${ }^{\circ}$ 54, pp. 21 y ss.

${ }^{73}$ ASÚA BATARRITA, Adela, "Concepto jurídico de terrorismo y elementos subjetivos de finalidad. Fines políticos últimos y fines de terror instrumental", en: ECHANO BASALDUA, Juan (Coord.), Estudios Jurídicos en memoria de José María Lidón, Bilbao: Universidad de Deusto, 2002, pp. 41-85, p. 7.

${ }^{74}$ PÉREZ CEPEDA, “Definición del delito de terrorismo”, cit. nota n 8, p. 63.
} 
Polít. crim. Vol. 11, No 21 (Julio 2016), Art. 6, pp. 140-172.

[http://www.politicacriminal.cl/Vol_11/n_21/Vol11N21A6.pdf]

\subsubsection{Finalidad de intimidación o provocación de terror.}

La finalidad de intimidar o de causar terror, a su vez puede ser exigida como efecto o resultado de la actividad terrorista, junto con la alarma pública; o bien como finalidad interna del sujeto.

Definiciones que aluden a los efectos o resultados de alarma pública o intimidación están en: el art. $139 \mathrm{CP}$ Federal Mexicano ("el que realice actos [...] que produzcan alarma, temor o terror en la población o en un grupo o sector de ella..."), el art. $144 \mathrm{CP}$ Colombiano ( "El que provoque o mantenga en estado de zozobra o terror a la población o a un sector de ella mediante actos...”), el art. 366 del Código Orgánico Integral Penal de Ecuador (en adelante COIP) ("la persona que individualmente o formando asociaciones armadas, provoque o mantenga en estado de terror a la población o a un sector de ella...”), el art.133 del CP Boliviano, que junto con la finalidad política contempla también el "mantener en estado de alarma o pánico colectivo a la población o a un sector de ella"; el art. 421-1 CP Francés ("cuando sean cometidos intencionadamente en relación con una acción individual o colectiva que tenga por objeto alterar gravemente el orden público mediante la intimidación o el terror...”).

Estas definiciones son tautológicas, pues definen terrorismo en base al terror, $\mathrm{y}$ hacen referencia a una especie de conmoción interna en la población o en los sujetos, que no es fácil de aprehender en derecho penal sustantivo, pues la estrecha relación "terrorismomedios de comunicación" impide arribar a conclusiones certeras respecto de quien causa realmente ese resultado de alarma pública o de temor. Al mismo tiempo, impiden diferenciar conductas terroristas de otras conductas de delincuencia común que también pudieran reclamar efectos de alarma pública ${ }^{75}$ (ej. estudiantes enardecidos atacando postes de alumbrado público o levantando barricadas), o intenciones de atemorizar a los eventuales sujetos pasivos (ej. narcotraficantes contra el cartel rival).

Sin embargo, tienen una ventaja respecto de aquellas que solo atienden a la finalidad política en el autor pues estas últimas desconocen normativamente la cualidad del uso de la violencia para generar miedo, como medio en la conducta del terrorista para alcanzar un fin político.

Respecto de las definiciones que acentúan el terror o la intimidación, como finalidad en el sujeto al momento de cometer la conducta, está el art. 1 de la Ley $\mathrm{N}^{\circ} 18.314$ chilena ("Constituirán delitos terroristas los enumerados en el artículo $2^{\circ}$, cuando el hecho se cometa con la finalidad de producir en la población o en una parte de ella el temor justificado de ser víctima de delitos de la misma especie...), el art. 41 quinquies $\mathrm{CP}$ argentino (Cuando alguno de los delitos previstos en este código hubiese sido cometido con la finalidad de aterrorizar a la población....").

El problema que presentan estos tipos penales es que psicologizan el concepto de terrorismo acarreando evidentes problemas de prueba, como ha sido develado por la

\footnotetext{
${ }^{75}$ VILLEGAS DÍAZ, "Los delitos de terrorismo”, cit. nota n 54, p. 14.
} 
VILLEGAS, Myrna. "Contribuciones para un concepto de terrorismo en el derecho penal chileno".

doctrina y jurisprudencia chilenas en relación al art. 1 de la Ley $\mathrm{N}^{\circ} 18.314^{76}$. Al mismo tiempo, impiden diferenciar conductas terroristas de otras conductas de delincuencia común como la de una barra de fútbol o de pandillas.

\subsubsection{Finalidad coactiva.}

La finalidad de obligar indebidamente a la autoridad y/o a una organización internacional a realizar un acto o abstenerse de ejecutarlo, es un elemento en el que ha venido insistiendo la legislación internacional comparada. Contemplan esta alusión la Ley $\mathrm{N}^{\circ} 18.314$ chilena (art. 1), el CP argentino (art. 144 quinquies) y CP Federal mexicano (art. 139). Ella tiene dos problemas, especialmente cuando es exigida en forma alternativa, esto es cuando la conducta típica se satisface mediante un acto cometido únicamente con esa finalidad coactiva y ninguna otra ${ }^{77}$, pero también, cuando esta finalidad coactiva es una de las formas a través de las cuales puede comprobarse la finalidad de causar temor (caso del art. 1 de la Ley $\left.\mathrm{N}^{\circ} 18.314\right)$ :

El primer problema es su amplitud, desde que permitiría tratar bajo supuestos de terrorismo, conductas que se encuentran al margen de dicho ámbito ${ }^{78}$. Por ejemplo, un motín penitenciario para obligar al gobierno a otorgar determinadas concesiones, o una banda de secuestradores que exige un helicóptero para salir del país, o delitos de incendios o amenazas cometidos en contra de privados para obligar al gobierno a no otorgar o cancelar permisos de construcciones de represas en territorios indígenas sagrados.

El segundo problema es que cuando esta finalidad se presenta como desvinculada completamente de la provocación de temor, podría llevar a castigar como terrorista una conducta que no persiga causar dicho temor en la población, con lo cual nos alejamos completamente de la esencia del fenómeno, y de los elementos exigidos a nivel internacional.

\subsection{Modelo Subjetivo - Objetivo.}

El modelo subjetivo objetivo es el que combina un elemento estructural relativo a la organización terrorista, con elementos subjetivos relativos a una determinada finalidad.

\footnotetext{
${ }^{76}$ VILLEGAS DÍAZ, "Los delitos de terrorismo", cit. nota n 54, p. 12; HERNÁNDEZ BASUALTO, Héctor, “Algunas modificaciones a la ley $\mathrm{N}^{\circ} 18.314$ ", Informe en Derecho III-2011, en: http://www.dpp.cl, p.7. [visitado el 05.05.2015]. Así por ejemplo, en un caso de colocación de artefacto explosivo causando daños a la propiedad, hecho calificado por el Ministerio Público como delito de terrorismo (art. $2 \mathrm{~N}^{\circ} 4$ en relación con art. 1 de la Ley $\mathrm{N}^{\circ}$ 18.314), la Corte de Apelaciones de Santiago no dio por probado el elemento subjetivo pues señaló que "la parte acusadora no demostró que la finalidad del imputado fuera la de producir en la población o en una parte de ella el temor justificado de ser víctima de delitos de la misma especie [...] ni la naturaleza del artefacto utilizado, ni las circunstancias de su utilización y ni los efectos obtenidos hacen factible arribar a esa conclusión fáctica.”. Sentencia Corte de Apelaciones de Santiago, 19 de noviembre de 2012, Rol N 2384-12 vs. Luciano Pitronello.

${ }^{77}$ Así sucede con la Decisión Marco europea (2002/475/JAI), cit. nota ${ }^{\circ} 17$, art. 270- sexies del CP italiano, $\S 129$ a del StGB alemán. En Latinoamérica, art. 44 quinquies del CP argentino y art. 139 del CP mexicano.

${ }_{78}$ GÓMEZ MARTÍN, Víctor, "Notas para un concepto funcional de terrorismo", en: SERRANO PIEDECASAS, José Ramón; DEMETRIO, Eduardo (Dirs.), Terrorismo y Estado de derecho, Madrid: Iustel, 2010, pp.25-52, p.28, VILLEGAS DÍAZ, "Los delitos de terrorismo", cit. nota n 54, p.14.
} 
Polít. crim. Vol. 11, No 21 (Julio 2016), Art. 6, pp. 140-172.

[http://www.politicacriminal.cl/Vol_11/n_21/Vol11N21A6.pdf]

En este modelo se ubicó el CP español hasta la reforma de la LO 5/2010, de 22 de junio. En ella los delitos de terrorismo se regularon en un capítulo especial que tipifica las organizaciones y grupos terroristas y los delitos de terrorismo, sobre la base de los siguientes elementos: Por un lado, la organización como injusto específico (art. 571) y a la vez como elemento de los tipos penales (art. 572), en esta reforma se relaja el concepto de organización terrorista, a consecuencia de la implementación de la Decisión Marco (2002/475/JAI), acuñándose también la noción de "grupo terrorista". Por otro lado, la finalidad política como elemento subjetivo del tipo penal, identificada con la "subversión del orden constitucional o alteración grave de la paz pública". El terrorismo era pues, organizado y con finalidad, contemplándose una figura específica para el terrorismo individual (art. 577) en la cual se contempla además de las finalidades anteriores, la de causar temor como forma de contribuir a la de subvertir el orden constitucional o alterar gravemente la paz pública, esto es, como medio ya no en la conducta sino en el elemento subjetivo.

Pero en la última reforma al CP español, LO 1/2015 de 30 de marzo, esta formulación cambia completamente. Por un lado, la organización terrorista sigue siendo un injusto específico (arts. 571 y 572) pero desaparece como elemento de los tipos penales de terrorismo, que se encuentran regulados en los arts. 573 y ss. Así las cosas, pareciera ser que en la actual formulación, la regla general sería el terrorismo individual para toda clase de delitos de terrorismo y no circunscritos únicamente a las hipótesis que antes contemplaba el art. 577, que desaparece completamente. Esta interpretación se vería reforzada por la formulación del art. 573 bis que al regular las penas, menciona expresamente para los delitos contra el orden público, una agravación "cuando se cometan por una organización o grupo terrorista o individualmente pero amparados en ellos". En los numerales anteriores no menciona la organización. El elemento subjetivo continua haciendo referencia a la subversión al orden constitucional y la alteración grave de la paz pública, pero añade para toda clase de delitos de terrorismo las finalidades de desestabilizar el funcionamiento de una organización internacional y la de provocar un estado de terror en la población o parte de ella. Además de lo anterior, entre otros, se tipifica como delito de terrorismo la imprudencia grave en la prevención del financiamiento (art. 576.4 en relación con art. 573.3 CP). El actual Código Penal ha sido criticado en forma unánime por la doctrina penal española aduciendo vulneración de garantías y una técnica legislativa muy deficiente ${ }^{79}$.

El CP italiano ubica los delitos de terrorismo dentro de los delitos contra el Estado, diseñando un concepto que realza por un lado el elemento estructural, la asociación terrorista, y las actividades que con ella se relacionan (pertenencia, reclutamiento, colaboración, adiestramiento), y por otro lado, la finalidad política. Asociaciones terroristas son las que persiguen fines de terrorismo internacional o la subversión del orden constitucional (art. 270 bis CP). Los delitos serán terroristas cuando puedan acarrear un grave daño a un país o a una organización internacional y se cometieren con la finalidad de intimidar a la población o presionar indebidamente a un gobierno o a una organización

\footnotetext{
79 Ver entre otros, comunicaciones del Grupo de Estudios de Política Criminal. http://www.gepc.es. Manifiesto de catedráticos de derecho penal de treinta y cinco universidades españolas. Disponible en: http://www.ub.edu/dpenal/recursos/TEXTO\%20FINAL2.pdf. [visitado el 28.08.2015]
} 
VILLEGAS, Myrna. "Contribuciones para un concepto de terrorismo en el derecho penal chileno".

internacional para que haga o deje de hacer algo, o para desestabilizar gravemente o destruir las estructuras fundamentales políticas, constitucionales, económicas o sociales de un país o de una organización internacional (art. 270 sexies). Así, las finalidades intimidatoria y coactiva aparecen como un medio en la conducta del terrorista. El terrorismo individual aparece difuso y simbólicamente referido a los delitos de colaboración con organización terrorista.

En nuestra Región, y dentro de la legislación comparada revisada, el único texto que contempla este tipo de modelo es el CP Boliviano, que ubica al terrorismo entre los delitos contra la seguridad interior del Estado (art. $133 \mathrm{CP}$ modificado por Ley $\mathrm{N}^{\circ} 170$ de 09.09.2011 de la Asamblea Legislativa Plurinacional de Bolivia). Sus elementos distintivos son: la consideración de la organización como elemento central en el tipo penal; el reconocimiento explícito a la finalidad política la que identifica con la subversión del orden constitucional o la intención de deponer al gobierno constitucionalmente elegido; la finalidad de causar alarma en la población, que es copulativa con la política y; los bienes jurídicos individuales a proteger se reducen a la seguridad común, vida e integridad corporal.

En este modelo de tratamiento, podemos ubicar también el último proyecto de ley que pretende reformar la ley de conductas terroristas en Chile (Boletín 9692-07) que cambia por completo el tipo penal pretendiendo emular el modelo de delito de organización ${ }^{80}$. Para lo cual define terrorismo en base a dos elementos, estructural y teleológico. Los concretos delitos que se cometen deben ser ejecutados por quienes pertenecen a una organización criminal. Ésta se define en base a la cantidad de sus miembros, su dotación de recursos y medios, la división de tareas o funciones, así como su capacidad de planificación e incidencia sostenida en el tiempo. Se castiga la pertenencia activa, la dirección en la organización, así como a todo aquel que haya tomado parte o ejecutado alguno de los delitos que describe la ley y hubiese adherido positivamente a los propósitos de la organización. La adhesión, puede consistir en "cualquier manifestación de voluntad expresa o tácita”, y exteriorizarse por cualquier medio: telefónico, electrónico o en redes sociales. Sugiere entonces que bastaría con un "me gusta" en Facebook. Inexplicablemente la propuesta incluye también la figura del "terrorista individual", aplicándole la misma pena que para el integrante. Todo lo cual contribuye a banalizar el concepto de terrorismo ${ }^{81}$, a la vez que produce un efecto criminógeno pues si la pena es la misma para el que actúa organizado que para el solitario, el terrorista preferirá organizarse para facilitar la ejecución, incrementándose así el riesgo para el bien jurídico protegido.

En cuanto a la finalidad terrorista, ésta puede consistir indistintamente en socavar o destruir el orden constitucional democrático, alterar el orden público, imponer exigencias o arrancar decisiones a la autoridad política, o infundir un temor generalizado en la población de

\footnotetext{
${ }^{80}$ Para ello reforma también el Código Procesal Penal estableciendo un proceso penal idéntico para el terrorismo y otras formas de criminalidad organizada. Aquí, solo se hará referencia a lo que dice relación con el concepto de terrorismo.

${ }^{81}$ En esta opinión MAÑALICH RAFFO, Juan Pablo, "El terrorismo ante el derecho penal: la propuesta legislativa del gobierno como retroceso", Anuario de Derecho Público Universidad Diego Portales, 2015, pp. 154-171, pp. 168-169.
} 
Polít. crim. Vol. 11, No 21 (Julio 2016), Art. 6, pp. 140-172.

[http://www.politicacriminal.cl/Vol_11/n_21/Vol11N21A6.pdf]

pérdida o privación de derechos humanos fundamentales. En este sentido, el tipo penal, contra las recomendaciones de la Corte Interamericana de Derechos Humanos ${ }^{82}$, es más amplio que el actual (que se construye solo en base a la finalidad de causar temor), y repite el mismo error al contemplar finalidades que si bien pueden ser un efecto de la actividad terrorista, no permiten respetar el principio de taxatividad y certeza. Se confunde el bien jurídico protegido en un delito de terrorismo, el orden constitucional de un Estado constitucional de derecho, con bienes jurídicos resguardados por otra clase de delitos que dicen relación con el orden y la tranquilidad pública. En este último punto preocupa que cualquier asociación pudiera convertirse en terrorista por el hecho de atentar contra el orden público $^{83}$, así como la dificultad para deslindar el terrorismo de la violencia social, o la violencia política no organizada, por cuanto dentro del catálogo están los desórdenes públicos del art. 6 de la Ley $\mathrm{N}^{\circ} 12.927$ sobre seguridad de Estado. Así, bastaría que un estudiante causara dichos desórdenes con la finalidad de arrancar una decisión a la autoridad política educacional, para que automáticamente pasara a ser considerado un delito de terrorismo.

De todas formas, debe reconocerse un acierto en la inclusión de la figura de apremios ilegítimos cometidos por funcionario público, la desaparición de delitos de incendio en propiedad privada que no cumple una función social, y la incorporación de una disposición expresa para castigar a la asociación criminal conformada para cometer genocidio o crímenes de Estado.

\section{Toma de postura: terrorismo como delito sui generis y sus elementos típicos.}

Considerando nuestra realidad como región, diversa de la europea y norteamericana, la "indefinición" de terrorismo tanto a nivel de las ciencias sociales como de la legislación internacional, y la suficiencia de nuestra legislación penal común y especial, mi opinión es que no debería legislarse sobre terrorismo en Chile, y derogarse la Ley $\mathrm{N}^{\circ} 18.314$, pues sobreabunda en lo ya existente. Sin embargo, la corriente político criminal va en dirección contraria, por lo que es necesario realizar un esfuerzo por encontrar algún sentido y racionalidad a una formulación típica, a fin de impedir que esa misma política criminal termine identificándose con la de un conflicto bélico. En este sentido, es importante considerar que en los delitos de terrorismo el principio de lesividad exige no tanto atentar (bajo forma de lesión o puesta en peligro) contra bienes jurídicos individuales, sino contra un bien jurídico colectivo, el orden constitucional democrático, entendido éste restrictivamente como la garantía constitucional de manifestarse a través de los cauces legales y materiales de participación democrática ${ }^{84}$. En torno a éste giran los elementos que deben estar presentes en una tipificación, y que a mi juicio son los que siguen:

\footnotetext{
${ }^{82}$ Sentencia Corte Interamericana de Derechos Humanos: Caso Norín Catrimán y otros vs. Chile, 29 de mayo de 2014, Serie C No. 279.

${ }^{83}$ MAÑALICH, "El terrorismo ante el derecho penal", cit. nota ${ }^{\circ} 81$, p. 169.

${ }^{84}$ Sobre la fundamentación del orden constitucional como bien jurídico protegido en los delitos de terrorismo, ampliamente VILLEGAS DÍAZ, Myrna, "Terrorismo: un problema de Estado. Tratamiento jurídico del terrorismo en la legislación comparada. Especial referencia a los delitos de terrorismo en las legislaciones de Chile y España", 2002, Cap. VI. Apartado Segundo, en: www.cybertesis.cl [visitado el 15.07.2015].
} 
VILLEGAS, Myrna. "Contribuciones para un concepto de terrorismo en el derecho penal chileno".

\subsection{Elementos teleológico e instrumental: La estrategia de comunicación por el terror y la idoneidad de los medios.}

Las conductas deben cometerse con la finalidad de alterar el orden constitucional o de derrocar a un gobierno legítimamente constituido. Pero éste no puede presentarse aislado en un tipo penal, pues lo reprochable en el terrorismo no es la finalidad en sí misma de alterar el orden constitucional, sino los medios que emplea. Se trata del "uso de violencia grave con fines políticos" $"$.

La finalidad de alterar el orden constitucional debe interpretarse como un elemento subjetivo de lo injusto y no un dolo específico. El dolo está referido a la realización de los elementos del tipo, no a la lesión del bien jurídico pues éste es previo al ilícito penal. Luego, el dolo abarca la conducta violenta e idónea para la lesión del bien jurídico, dejando fuera lo que el autor pretenda lograr con su conducta. Esta finalidad debería -de lege ferenda- construirse como un elemento subjetivo de tendencia interna intensificada. Esto es, una finalidad que pudiera servir para determinar el tipo penal, precisando la conducta típica.

De esta forma, la consumación en los delitos de terrorismo se produciría cuando se comprobare al menos el resultado de peligro (concreto) para el bien jurídico colectivo, para lo que cual haría falta la producción de los actos ejecutivos ${ }^{86}$.

Pero la finalidad política no basta, pues un elemento definitorio del terrorismo es la provocación de temor o terror en la población ${ }^{87}$, que técnicamente es un "medio en la conducta" 88 para alcanzar el objetivo político. El "terror" no deriva de los fines que persigue la actividad terrorista (que se pretenda instaurar un gobierno distinto afín a ciertos intereses, o que se quiera destruir los cimientos mismos del Estado) sino de la lesividad de los medios, pues éstos deben ser idóneos para causar terror ${ }^{89}$, siendo los objetivos relevantes hasta el punto que condicionen la valoración de los medios ${ }^{90}$. A través de medios idóneos es que el terrorismo usa el terror como estrategia de comunicación y entrega su mensaje al Estado, más allá de solo disputarle el monopolio de la violencia, cuestiona los mecanismos de toma de decisiones al Estado ${ }^{91}$.

Luego, junto con la finalidad política, es necesaria la referencia a los medios a utilizar por el terrorismo ${ }^{92}$. Con esta interpretación, no solo no tiene sentido contemplar expresamente

\footnotetext{
${ }^{85}$ TERRADILLOS BASOCO, "El Estado de derecho", cit. nota n 5, p. 274.

${ }^{86}$ Ampliamente VILLEGAS DÍAZ, "Los delitos de terrorismo", cit. nota n 54, pp. 14-15.

87 Así ASÚA BATARRITA, "Concepto jurídico de terrorismo, cit. nota $\mathrm{n}^{\circ}$ 73, p. 28, TERRADILLOS BASOCO, "El Estado de derecho", cit. nota n 5, pp. 272 a 275, CARNEVALI, "El Derecho Penal Frente al Terrorismo", cit. nota ${ }^{\circ} 66$, p. 128.

${ }^{88}$ A/RES/51/210 de 16.01.1997, A/RES/52/164 de 09.01.1998

${ }^{89}$ TERRADILlOS BASOCO, "El Estado de derecho", cit. nota n ${ }^{\circ}$ 5, p. 275. Similar, VILLEGAS DÍAZ, "Los delitos de terrorismo", cit. nota n 54, p.30; AMBOS, El derecho penal, cit. nota n ${ }^{\circ} 35$, pp.47-48: "siempre que se cometan ataques individuales contra civiles con el propósito de ocasionar miedo y terror se estará ante un delito de terrorismo, puesto que los medios y métodos utilizados son terroristas"

90 TERRADILLOS BASOCO, "El Estado de derecho", cit. nota n 5, p. 275.

${ }^{91}$ CANCIO MELIÁ, Los delitos de terrorismo, cit. nota ${ }^{\circ} 34$, p. 184.

${ }^{92}$ Se rescata en este punto el CP mexicano (art. 139) y el COIP de Ecuador (art. 366) que hacen referencia
} 
Polít. crim. Vol. 11, No 21 (Julio 2016), Art. 6, pp. 140-172.

[http://www.politicacriminal.cl/Vol_11/n_21/Vol11N21A6.pdf]

una finalidad coactiva (obligar a la autoridad o a una organización internacional a que haga o deje de hacer algo), sino asimismo evita que se califiquen como terroristas conductas que no persiguen atemorizar a la población sino simplemente arrancar una decisión a los poderes públicos (ej. una huelga de estudiantes por políticas educacionales), que es el problema que tienen en este momento gran parte de las legislaciones europeas ${ }^{93}$.

La causación de temor o terror no debe aparecer descrita en un tipo penal por las razones expuestas, mucho menos como una "finalidad", pues ella es un "efecto" o resultado de la actividad terrorista producto de los medios que ésta utiliza. Con la sola referencia a los medios se eliminaría el riesgo de psicologización, o de manipulación mediática de tales efectos.

\subsection{La organización terrorista.}

La violencia debe ser sistemática para generar temor ${ }^{94}$, entendiendo que sistematicidad no es simplemente reiteración de actos, sino potencialidad criminal. Ella solo es posible cuando hay una organización criminal, debiendo exigirse su presencia jurídicamente en el tipo penal, pues sin organización no parece haber posibilidades de materializar la afectación al bien jurídico (como puesta en peligro). En este punto es importante detenerse, pues normativamente en varias legislaciones se admite el terrorismo individual, también en el actual proyecto de ley que pretende reformar la Ley $\mathrm{N}^{\circ}$ 18.314. En Latinoamérica es la regla general como se observa de los arts. 1de la Ley $\mathrm{N}^{\circ} 18.314$ en Chile, art. $139 \mathrm{CP}$ Federal de México, art. 391 CP de Guatemala, art. 343 CP de Colombia, art. 366 COIP de Ecuador, art. 41 quinquies CP de Argentina. Se exceptúa de esta regla, el CP de Bolivia (art. 133) que considera la organización como elemento central en el tipo penal, y no tiene terrorismo individual.

Estados Unidos tampoco considera la organización como elemento central del tipo penal, pues prácticamente no hace referencia a ella en ninguna de las definiciones (secciones 802 y 808, USA PATRIOT ACT, Act of 2001, Uniting and Strengthening America by Providing Appropriate Tools Required to Interrupt and Obstruct Terrorism).

En Europa se tipifica el terrorismo organizado y como excepción el terrorismo individual ${ }^{95}$. Este último tiene un origen histórico ideológico, pues nace a instancias del marxismo, para identificarlo con la violencia sectaria, esto es, aquella desvinculada de las masas atribuida

expresa a medios catastróficos o violentos para la comisión de la conducta. La ley 18.314 antes de la modificación introducida por la ley 20.467 de 8 de octubre de 2010, también hacía referencia a este tipo de medios, pero no condicionaba la conducta a su comisión. Su función era dar concreción a una presunción de la finalidad terrorista establecida en la ley (norma que fue derogada) pero servía como criterio interpretativo. VILLEGAS DÍAZ, Myrna, "Estado de excepción y antiterrorismo en Chile. Criminalización de la protesta social con especial referencia a los indígenas", Revista de Derecho Penal y Criminología. Año III, $\mathrm{N}^{\circ} 6$ (2013), pp. 3-25, pp. 21-22.

${ }_{93}^{93}$ GÓMEZ MARTÍN, "Notas para un concepto", cit. nota nº 78, pp. 28 y 29.

${ }^{94}$ La coherencia y la persistencia son la clave del éxito para los terroristas. DE LA CORTE IBÁÑEZ, Luis, "Aproximación psicosocial al análisis de los movimientos terroristas", en: CANCIO, Manuel; POZUELO, Laura (Coords.), Política criminal en vanguardia. Inmigración clandestina, terrorismo, criminalidad organizada, Madrid: Thompson Civitas, 2008, pp. 325-373, p. 343.

${ }^{95}$ Salvo la última reforma al CP español. 
VILLEGAS, Myrna. "Contribuciones para un concepto de terrorismo en el derecho penal chileno".

al populismo y anarquismo, por oposición a la violencia de masas ${ }^{96}$. Pero ese "terrorismo individual" o "violencia sectaria" estaba también organizado, se trataba primero de Narodnaia Volia y más tarde del Partido Socialista Revolucionario. Así, mirado en sus orígenes no existen "terroristas individuales" que operen al margen de una organización. Incluso, se cuestiona a los "lobos solitarios" del yihadismo, pues suelen estar integrados en pequeñas células dentro de una red global, y obedecen a un mando que da las órdenes ${ }^{97}$.

Por ello es que la doctrina en general ${ }^{98}$ rechaza la incriminación, a título de terrorismo, de actos perpetrados al margen de una organización, pues sin ella no parece posible la afectación del orden constitucional democrático. Por el contrario, la organización terrorista en el injusto permite distinguir al terrorismo de la violencia social o de la violencia espontánea no organizada con finalidad política, por ejemplo, la de piquetes de huelga de trabajadores, estudiantiles o movimientos antiglobalización ${ }^{99}$.

\subsubsection{Dimensión y estructura de la organización terrorista.}

La organización debe tener una dimensión y estructura suficientes como para llevar a cabo una tarea de la envergadura que se ha propuesto: afectar el monopolio de la violencia del Estado $^{100}$. Y para ello, debe contar con cierto grado de jerarquía, un férreo proceso de socialización de sus miembros, estabilidad, permanencia, recursos y una suficiente red de apoyo y relaciones sociales ${ }^{101}$, en suma, debe mostrar una idoneidad para poder realizar los concretos delitos que se ha propuesto, idoneidad que viene dada por la dotación de medios, hombres y estructuras ${ }^{102}$. En este sentido se han pronunciado tribunales penales en Chile ${ }^{103}$.

\footnotetext{
96 MORAL DE LA ROSA, Juan, Aspectos penales y criminológicos del terrorismo, Madrid: Centro de Estudios Financieros, 2005, p. 22.

${ }^{97}$ Entrevista a Jean Pierre Filiú: “Démonter le mythe du loup solitaire!”, Le Point.fr. 15-01-2015. Disponible en http://www.lepoint.fr/societe/jean-pierre-filiu-demonter-le-mythe-du-loup-solitaire-15-01-20151896780_23.php [visitado el 01.04.2015].

${ }^{98}$ En España, entre otros, GRUPO DE ESTUDIOS DE POLITICA CRIMINAL, Una alternativa a la actual política criminal sobre terrorismo, Documentos 9 (2008), Valencia: Tirant Lo Blanch, pp.35-36, CANCIO MELIÁ, "Los delitos de terrorismo", cit. nota n 34, pp. 259 y ss., GÓMEZ MARTÍN, "Notas para un concepto", cit. nota n 78, p. 41. LAMARCA PÉREZ, Carmen, "La regulación del terrorismo en el código penal español”, en: PÉREZ, Fernando; NÚÑEZ PAZ, Miguel; GARCÍA, Isabel (Coords.), Universitas Vitae. Homenaje a Ruperto Núñez Barbero, Salamanca: Ediciones Universidad de Salamanca, 2014, pp. 359-372, p. 368. En principio también LLOBET ANGLÍ, Mariona, Derecho penal del terrorismo. Límites de su punición en un Estado democrático, Madrid: La Ley, 2010, pp. 86-89, aunque admite la posibilidad de terrorismo individual cuando se use un arma de destrucción masiva por parte de un sujeto. En Chile, DEL BARRIO, Álvaro; LEON REYES, Julio, Terrorismo, ley antiterrorista y derechos humanos, Santiago de Chile: Programa de Derechos Humanos, Academia de Humanismo Cristiano, 1990, p. 206, MAÑALICH, "El terrorismo ante el derecho penal", cit. nota ${ }^{\circ} 81$, pp. 168-169.

99 Ampliamente VILLEGAS DÍAZ, "Los delitos de terrorismo", cit. nota n 54, pp. 15-19.

${ }^{100}$ CANCIO MELIÁ, "Los delitos de terrorismo", cit. nota n 34, p. 156.

${ }^{101}$ DE LA CORTE, “Aproximación psicosocial”, cit. nota n 94, pp. 347 y 352.

${ }^{102}$ SILVA SÁNCHEZ, "La intervención”, cit. nota n 62, pp. 87-134, p. 99.

103 Sentencia Tribunal Oral en Lo Penal de Temuco, 27 de julio de 2005, RUC 0200142499 - 0 , vs. Patricia Troncoso y otros: “...les habrían dicho debian llevar [...] palos, boleadoras, piedras, herramientas agrícolas, y botellas y combustible para armar bombas molotov; es efectivo que el fuego por sí solo puede constituir un arma letal que causa estrago, y para encenderlo basta un fósforo, pero no puede ser el único elemento bélico con que se cuente para una guerra separatista. Tampoco una estructura horizontal, esto es, mediante células que actúan coordinadamente pero en forma independiente, se condice con el liderazgo que
} 
Polít. crim. Vol. 11, No 21 (Julio 2016), Art. 6, pp. 140-172.

[http://www.politicacriminal.cl/Vol_11/n_21/Vol11N21A6.pdf]

Se ha venido insistiendo en el último tiempo que el terrorismo ha ido cambiando sus formas, y que ya las organizaciones terroristas clásicas, con una estructura piramidal, jerárquica, prácticamente no existen. Este discurso ha cobrado mucha fuerza en Europa, a propósito del terrorismo islámico y su organización "mercurial" donde las "redes" cobran gran importancia ${ }^{104}$.

Ello provocó la relajación del elemento estructural al punto de considerar suficientes a grupos de tres personas, en algunos casos sin necesidad de permanencia ni estabilidad. Esta tendencia que en algunos países ya existía ${ }^{105}$, no sin duras críticas doctrinarias, se vio fortalecida con la consideración normativa del terrorismo como crimen organizado y los parámetros que da la Convención de Palermo, cuyo artículo 2 define el "grupo delictivo organizado" como el grupo estructurado de tres o más personas, con cierta permanencia en el tiempo que actúa para cometer los delitos definidos en la convención. A su vez define "grupo estructurado" como un grupo no formado fortuitamente para la comisión inmediata de un delito y en el que no necesariamente haya asignación formal de roles a sus miembros.

Con estas definiciones el concepto de terrorismo se va desdibujando, hasta llegar a concebir como terroristas a tres personas que se dedican durante algún tiempo a causar daños a sucursales bancarias con artefactos incendiarios o explosivos de baja intensidad, lo cual se aleja completamente de la estrategia de dominación y de comunicación por el terror que define al terrorismo para alcanzar un fin político.

De ahí que la doctrina, se esfuerce por encontrar límites a esta expansión ${ }^{106}$, recordando que "la estructura del colectivo terrorista ha de ser extraordinariamente densa" "107, y que si no se tiene este elemento en consideración, se corre el riesgo de identificar estos grupos con situaciones de codelincuencia o de simple conspiración para delinquir ${ }^{108}$. Por ello, y refiriéndonos especialmente al terrorismo islámico, aunque este colectivo no se integre en forma piramidal, sino a través de grupos, células o comandos, éstos, necesariamente deberían formar parte de una organización mayor, o una red terrorista.

deben ejercer una o más personas para llevar a buen término una lucha independentista"'(considerando décimo primero).

${ }^{104}$ Sobre este funcionamiento mercurial, véase BORDAS MARTÍNEZ, Julio, El terrorismo yihadista en la sociedad calidoscópica (aproximación criminológica al nuevo terrorismo del siglo XXI), Madrid: Edisofer, 2006, pp. 207 y ss.

${ }^{105}$ FARALDO CABANA, Patricia, Asociaciones ilícitas y organizaciones criminales en el código penal español, Valencia: Tirant Lo Blanch, 2012, pp. 117 y ss.

106 FARALDO CABANA, Asociaciones ilícitas, cit. nota ${ }^{\circ} 105$, pp. 116 y ss. Cfr. LLOBET ANGLí, Derecho penal del terrorismo, cit. nota $\mathrm{n}^{\circ} 98$, pp. 185 y ss., quien se esfuerza por expandirlo considerando que "las asociaciones de personas que sin formar parte directa de una banda armada, la cual es el núcleo de la actividad terrorista, coadyuvan con sus actividades han de ser consideradas organizaciones o grupos de tal naturaleza" (p.185). Sin embargo, distingue en cuanto a la pena la que considera debe ser más baja que la de la organización terrorista.

${ }^{107}$ CANCIO MELIÁ, Los delitos de terrorismo, cit. nota ${ }^{\circ} 34$, p. 66

108 LAMARCA PÉREZ, "La regulación del terrorismo", cit. nota n 98, p.363. Críticamente respecto de la reforma de la LO 5/2010 respecto de este punto CANCIO MELIÁ, Manuel, "Delitos de organización: criminalidad organizada común y delitos de terrorismo", en: DÍAZ MAROTO y VILLAREJO, Julio (Dir.), Estudios sobre las reformas del Código Penal (operadas por las LO 5/2010, de 22 de junio y $3 / 2011$ de 28 de enero, Madrid: Civitas, 2011, pp. 643-670, pp. 651 - 653. 
VILLEGAS, Myrna. "Contribuciones para un concepto de terrorismo en el derecho penal chileno".

4.2.2. El rol de la organización en el injusto penal.

El hecho de que el terrorismo necesite contar con una organización de esta envergadura no necesariamente debe reconducirnos a un injusto específico de asociación ilícita terrorista como base de la punición, en cuyo marco se cometan los concretos delitos por parte de sus miembros y colaboradores. Complementando lo antes dicho al observar el modelo de delitos de organización, hay algunas cuestiones que debemos resolver: a) Si es sostenible la idea de un injusto de organización terrorista como posibilidad real de afectación al monopolio estatal de la violencia, b) Si es adecuado atribuir responsabilidad penal por la mera pertenencia a la organización, c) cuál sería la ubicación de la organización en los injustos de terrorismo y d) cómo se sanciona a los que colaboran con la organización.

En cuanto a lo primero, es dudoso que las organizaciones terroristas tengan la capacidad de afectar la existencia del Estado, pues no están en condiciones de competir en términos bélicos con él ${ }^{109}$. Si así fuese, cambiaría el curso de la historia de ese respectivo Estado y los que antes fueron terroristas, serían considerados héroes nacionales (lo que da cuenta también del carácter pendular del concepto de terrorismo). La consecuencia sustantivo penal es que si consideramos que el terrorismo afecta a la existencia misma del Estado, en términos de "embestirlo en su esencia"110 por el hecho de atacar su hegemonía y poder jurídicos, tendría que ser concebido como un delito contra la seguridad del Estado (caso del terrorismo internacional yihadista), y no como un delito contra el orden constitucional ${ }^{111}$. Por lo que perdería sentido la incriminación de la asociación terrorista. Por otra parte, si estamos conscientes que ninguna organización terrorista puede afectar la existencia del Estado, el injusto tendría que construirse como un delito de peligro abstracto en relación al bien jurídico colectivo que se pretendería proteger.

Pero supongamos que esta teoría hace referencia a la eventual capacidad de organizaciones que operan al interior de los Estados no para afectar a estos, sino el orden constitucional ${ }^{112}$. La carencia de esta capacidad por parte de la o las concretas organizaciones determinaría que los delitos que la organización cometiera serían delitos comunes probablemente agravados por alguna circunstancia (la de actuar en grupo, o la de utilizar métodos catastróficos, etc.). Cuestión relevante porque de lo contrario, el terrorismo como concepto jurídico se abre extraordinariamente, permitiendo cobijar conductas desplegadas por grupos, que no tienen idoneidad para afectar los canales de participación como manifestación de la voluntad popular.

Esta capacidad de afectar el orden constitucional queda demostrada entonces por los concretos delitos que se cometen en el marco de la organización, que deben ser idóneos para perturbar la estabilidad democrática de un país, lo que permitiría construir el injusto de

\footnotetext{
${ }^{109}$ CANCIO MELIÁ, Los delitos de terrorismo, cit. nota n ${ }^{\circ} 34$, p. 45, citando a Lord Hoffman en la sentencia de la Cámara de Lores de 2004, respecto de la normativa antiterrorista británica aparecida tras los atentados de $11 \mathrm{~S}$.

${ }^{110}$ GUZMÁN DALBORA, Estudios, cit. nota n 43, p.230.

${ }^{111}$ En esta opinión José Ramón Serrano-Piedecasas Fernández, Entrevista realizada en Madrid, 18 de octubre 2014.

${ }^{112}$ Cfr. GUZMÁN DALBORA, Estudios, cit. nota n 43, p. 220 quien sugiere que la teoría hace referencia al orden público.
} 
Polít. crim. Vol. 11, No 21 (Julio 2016), Art. 6, pp. 140-172.

[http://www.politicacriminal.cl/Vol_11/n_21/Vol11N21A6.pdf]

terrorismo como un delito de peligro concreto en relación al bien jurídico colectivo que se pretende proteger. Y por ende, el injusto de la asociación criminal quedaría constituido una vez que se diera inicio a la ejecución de tales delitos, al menos en grado de tentativa, lo que implica que los delitos concretos que se cometen, deben ser anteriores a la constitución de la asociación ${ }^{113}$. De ahí que, como sugiere Jesús Silva, la pertenencia a una organización no pueda ser un criterio de atribución de responsabilidad por algo distinto, sino simplemente el objeto de una atribución de responsabilidad que es individual ${ }^{114}$. Con esto respondemos a la segunda interrogante.

Por ello es que la organización, en mi opinión, debe configurarse como un auténtico elemento de los tipos penales de terrorismo ${ }^{115}$, y no como un injusto específico de asociación terrorista a partir del cual puedan cometerse otros delitos que son comunes (modelo de delitos de organización). Respondemos así a la tercera interrogante. La exigencia de la pertenencia a una organización terrorista como elemento del tipo, impediría el castigo simultáneo por el delito de terrorismo cometido y por el de asociación terrorista (ne bis in ídem).

La mera pertenencia del sujeto a una asociación criminal quedaría entregada a las reglas generales del art. 292 del Código Penal, sin perjuicio que su decimonónica formulación exija una urgente revisión. Luego, el problema no reside en si debe tipificarse una asociación ilícita terrorista autónoma, sino en cómo se reformula la asociación ilícita común, tema que escapa a los objetivos de este artículo, pero nos permite sugerir que en esa reformulación, la especificidad del terrorismo podría constituirse, a lo sumo, como una agravación de la pena. Con todo, nuevamente el principio de ne bis in ídem impediría castigar el delito concreto cometido y a la vez por el de asociación ilícita agravado por su carácter terrorista, quedando este último, de lege data, reservado para aquellos casos en los que no hubiese delito concreto cometido ${ }^{116}$.

En este esquema, la conducta de los colaboradores quedaría entregada a las reglas generales de participación criminal tanto si se trata de colaboración en el concreto delito de terrorismo que se cometa, como de colaboración en la asociación ilícita.

Se descarta la posibilidad de que la organización terrorista pueda constituirse en una condición objetiva de punibilidad en lugar de un elemento del tipo, pues ello tendría efectos en el injusto contradictorios con lo aquí sostenido. Esto porque al no ser la punibilidad un elemento autónomo del delito, la ausencia de la pertenencia del sujeto a la organización terrorista al cometer el concreto delito de que se tratare, conduciría a considerar la existencia de un injusto de terrorismo, al margen de una organización, solo que no punible a título de terrorismo sino como delito común. Así las cosas, podría existir un injusto de

\footnotetext{
${ }^{113}$ GUZMÁN DALBORA, Estudios, cit. nota n ${ }^{\circ} 43$, p.219.

${ }^{114}$ En esta interpretación de la postura de Silva Sánchez, MAÑALICH, "Organización delictiva”, cit. nota $n^{\circ}$ 40, p. 291.

${ }^{115}$ En el mismo sentido LAMARCA PÉREZ, “La regulación del terrorismo”, cit. nota n 98, p.360.

${ }^{116}$ Se insiste en que esta solución es de lege data por cuanto aun cuando su autora está en desacuerdo con la punición autónoma de la asociación ilícita, no puede prescindirse del marco normativo que nos rige.
} 
VILLEGAS, Myrna. "Contribuciones para un concepto de terrorismo en el derecho penal chileno".

terrorismo al margen de una organización, es decir, terrorismo individual, pero que por razones de política criminal debería ser castigado como delito común.

\section{Conclusiones}

Cualquier reforma legal que intente realizarse en Chile sobre tipos penales de terrorismo debe considerar nuestras particularidades como país latinoamericano, y observar con atención las consecuencias, especialmente político criminales que pudiera traer la adopción de alguno de los modelos de tratamiento jurídico aquí examinados. Muy especialmente debe mirarse con atención las particularidades criminológicas y político criminales asociadas al terrorismo que pudieran hacer aconsejable o desaconsejable una determinada opción. A su vez debe ser capaz de distinguir entre el terrorismo internacional y el terrorismo interno.

El terrorismo internacional, se ha dicho, se configura como un ataque a la seguridad exterior de los Estados, y los actos que comete más bien pueden encuadrarse dentro de crímenes de lesa humanidad, como ha sucedido con el exterminio de cristianos por parte del estado islámico. De ahí que su regulación debiera ser distinta, y su investigación excede los límites de este trabajo.

A efectos del derecho penal interno, y considerando que mediante este tipo de figuras se intenta proteger un régimen democrático amparado en la libre determinación de los pueblos, el orden constitucional democrático como bien jurídico protegido ofrece una opción determinada y determinable a partir de la cual puedan construirse tipos penales de peligro concreto.

La tendencia mundial va hacia la consagración de tipos penales sui generis de terrorismo, y así lo demuestran los recientes esfuerzos doctrinales y legislativos en Chile plasmados en el anteproyecto de código penal de diciembre de 2013, en el informe de la comisión de expertos de octubre de 2014 y el proyecto de ley vigente sobre terrorismo, todos ya examinados y cotejados entre sí. En esta tendencia, el aporte de este trabajo ha consistido en reexaminar el tema considerando nuevos aportes plasmados en bibliografía actualizada, situándose la autora como tábula rasa frente al fenómeno respecto de sus investigaciones anteriores sobre el mismo, no obstante lo cual, puede señalar que después de haber examinado las nuevas tendencias en esta clase de delitos sigue sosteniendo un modelo similar al planteado en su día, fundamentalmente mirando el asunto desde el derecho penal de las consecuencias. Por ello, mantiene su posición inicial en cuanto a que en un concepto de terrorismo como delito sui generis deben estar presentes: a) la finalidad política (alterar el orden constitucional), b) medios idóneos para causar terror (especialmente catastróficos), c) conductas que importen violencia grave (atentados contra la vida, la integridad física, la libertad y la propiedad pública), y d) la organización terrorista como elemento del tipo y no como fundante del injusto.

La variación consiste en otorgar una importancia aun mayor a la idoneidad de los medios para provocar terror, que es el rasgo probablemente distintivo del terrorismo asociado a la 
Polít. crim. Vol. 11, № 21 (Julio 2016), Art. 6, pp. 140-172.

[http://www.politicacriminal.cl/Vol_11/n_21/Vol11N21A6.pdf]

finalidad política. De esta forma, siendo el medio idóneo, hay un elemento de carácter objetivo en el tipo penal que impediría una psicologización del concepto.

Sin perjuicio de lo anterior, el Estado constitucional de derecho debe considerar que cuando una organización terrorista, además de sus armas cuenta con un sustrato ideológico indestructible, es muy difícil que abandone la violencia. Si a ello se une que existen organizaciones legales que si bien no comparten la violencia como método, pero sí los objetivos de la organización, el abandono de la violencia se torna aún más complejo. Luego, el problema del terrorismo no es de eficacia policial, ni de políticas criminales conducentes a degradar los instrumentos penales y procesales, sino de falta de discusión política. La única derrota certera del terrorismo es en el plano ideológico. 
VILLEGAS, Myrna. "Contribuciones para un concepto de terrorismo en el derecho penal chileno".

\section{BIBLIOGRAFIA CITADA}

ABAD CASTELOS, Montserrat, "El concepto de terrorismo y los problemas relativos a su ausencia en el ámbito de las Naciones Unidas", en: CONDE, Elena (Dir.) e IGLESIAS, Sara (Coord.), Terrorismo y legalidad internacional, Madrid: Dykinson, 2012, pp. 105-126.

AMBOS, Kai, El derecho penal frente a amenazas extremas, Madrid: Dykinson, 2007.

ASÚA BATARRITA, Adela, "Concepto jurídico de terrorismo y elementos subjetivos de finalidad. Fines políticos últimos y fines de terror instrumental", en: ECHANO BASALDUA, Juan (Coord.), Estudios Jurídicos en memoria de José María Lidón, Bilbao: Universidad de Deusto, 2002, pp. 41-85.

BORDAS MARTÍNEZ, Julio, El terrorismo yihadista en la sociedad calidoscópica (aproximación criminológica al nuevo terrorismo del siglo XXI), Madrid: Edisofer, 2006.

CANCIO MELIÁ, Manuel, Los delitos de terrorismo: estructura típica e injusto, Madrid: Reus, 2010.

, "El delito de pertenencia a una organización terrorista en el Código Penal Español", en: LUZÓN PEÑA, Diego (Dir), Derecho Penal del Estado Social y Democrático de Derecho. Libro Homenaje a Santiago Mir Puig, Madrid: La Ley, 2010, pp. 987-1010.

"Delitos de organización: criminalidad organizada común y delitos de terrorismo", en: DÍAZ MAROTO y VILLAREJO, Julio (Dir.), Estudios sobre las reformas del Código Penal (operadas por las LO 5/2010, de 22 de junio y 3/2011 de 28 de enero, Madrid: Civitas, 2011, pp. 643-670.

CANCIO MELIÁ, Manuel y SILVA SÁNCHEZ, Jesús, Delitos de organización, Montevideo: Buenos Aires, BdF, 2008.

CARNEVALI RODRÍGUEZ, Raúl, "El Derecho Penal Frente al Terrorismo. Hacia un modelo Punitivo Particular y Sobre el Tratamiento de la Tortura", Revista de Derecho de la P. Universidad Católica de Valparaíso, Vol. XXXV (2ºm. 2010), pp. 109145.

CASTILLO BARRANTES Enrique et. Al., "Criminalidad Organizada. Informe General de la Sociedad Internacional de Criminología”, Trad. GERMÀN, Isabel, Cuadernos de Política Criminal, n 50 (1990), pp. 493-512.

DEL BARRIO, Álvaro; LEON REYES, Julio, Terrorismo, ley antiterrorista y derechos humanos, Santiago de Chile: Programa de Derechos Humanos, Academia de Humanismo Cristiano, 1990.

DE LA CORTE IBÁÑEZ, Luis, “Aproximación psicosocial al análisis de los movimientos terroristas”, en: CANCIO, Manuel; POZUELO, Laura (Coords.), Política criminal en vanguardia. Inmigración clandestina, terrorismo, criminalidad organizada, Madrid: Thompson Civitas, 2008, pp. 325-373.

DONINI, Massimo, "Derecho penal de lucha. Lo que el debate sobre el derecho penal del enemigo no debe limitarse a exorcizar", en: CANCIO, Manuel; POZUELO, Laura (Coords.), Política criminal en vanguardia. Inmigración clandestina, terrorismo, criminalidad organizada, Madrid: Thompson Civitas, 2008, pp. 29-75. 
Polít. crim. Vol. 11, No 21 (Julio 2016), Art. 6, pp. 140-172.

[http://www.politicacriminal.cl/Vol_11/n_21/Vol11N21A6.pdf]

ESCRIBANO UBEDA, José, Terrorismo, narcotráfico, blanqueo de capitales, trata de personas, tráfico ilícito de migrantes, tráfico ilícito de armas: Lucha global contra la delincuencia organizada transnacional, Madrid: Visión Libros, 2009.

FARALDO CABANA, Patricia, Asociaciones ilícitas y organizaciones criminales en el código penal español, Valencia: Tirant Lo Blanch, 2012.

FERNÁNDEZ REQUENA, Juan, El delito de terrorismo urbano o de baja intensidad. Análisis del artículo 577 CP, Valencia: Tirant Lo Blanch, 2009.

FERRAJOLI, Luigi, Derecho y Razón. Teoría del garantismo penal, Trad.: IBÀÑEZ, Perfecto; TERRADILLOS, José et. al, Madrid: Trotta, 1995.

FINKLEA, Kristin, "Organized Crime in the United States: Trends and Issues for Congress", Documentos de investigación del Congreso de los EE.UU, 2010, disponible en: http://www.fas.org/sgp/crs/misc/R40525.pdf.

GARCÍA RIVAS, Nicolás, "La tipificación "europea" del delito terrorista en la Decisión Marco de 2002". Análisis y perspectivas", en: PÉREZ, Fernando; NÚÑEZ PAZ, Miguel; GARCÍA, Isabel (Coords.), Universitas Vitae. Homenaje a Ruperto Núñez. Barbero, Salamanca: Ediciones Universidad de Salamanca, 2014, pp. 272-302.

GÓMEZ MARTÍN, Víctor, "Notas para un concepto funcional de terrorismo", en: SERRANO PIEDECASAS, José Ramón; DEMETRIO, Eduardo (Dirs.), Terrorismo y Estado de derecho, Madrid: Iustel, 2010, pp. 25-52.

GONZÁLEZ CUSSAC, José Luis, “Tecnocrimen” en: GONZÁLEZ, José Luis; CUERDA, María Luisa (Dirs.), FERNÁNDEZ, Antonio (Coord.), Nuevas amenazas a la seguridad nacional. Terrorismo, criminalidad organizada y tecnologías de la información y la comunicación, Valencia: Tirant Lo Blanch, Monografías 833, 2013, pp. 205-241.

GRUPO DE ESTUDIOS DE POLITICA CRIMINAL, Una alternativa a la actual política criminal sobre terrorismo, Documentos 9 (2008), Valencia: Tirant Lo Blanch.

, Una propuesta de renovación de la política criminal sobre terrorismo, Documentos 14 (2013), Valencia: Tirant Lo Blanch.

GUZMÁN DALBORA, José Luis, "El terrorismo como delito común”, en: AMBOS, Kai. Terrorismo y Derecho penal, Bogotá: Konrad Adenauer, 2015, pp.401-438

Estudios y Defensas Penales, Santiago de Chile: Legal Publishing, 2009.

HERNÁNDEZ BASUALTO, Héctor, "Algunas modificaciones a la ley $\mathrm{N}^{\circ} 18.314$ ", Informe en Derecho III-2011, en: www.dpp.cl

LAMARCA PÉREZ, Carmen, "La regulación del terrorismo en el código penal español", en: PÉREZ, Fernando; NÚÑEZ PAZ, Miguel; GARCÍA, Isabel (Coords.). Universitas Vitae. Homenaje a Ruperto Núñez Barbero, Salamanca: Ediciones Universidad de Salamanca, 2014, pp. 359-372.

LANDA GOROSTIZA, Jon, "La sombra de los crímenes contra la humanidad en la política antiterrorista española: Reflexiones críticas”, Revista electrónica de ciencia penal y criminología 12-10 (2010), pp. 1-30, en: http://criminet.ugr.es/recpc.

LLOBET ANGLÍ, Mariona, Derecho penal del terrorismo. Límites de su punición en un Estado democrático, Madrid: La Ley, 2010.

MAÑALICH RAFFO, Juan Pablo, "El terrorismo ante el derecho penal: la propuesta legislativa del gobierno como retroceso", Anuario de Derecho Público Universidad Diego Portales, 2015, pp. 154-171.

, "Organización delictiva. Bases para su elaboración dogmática en el derecho penal 
VILLEGAS, Myrna. "Contribuciones para un concepto de terrorismo en el derecho penal chileno".

chileno", Revista Chilena de Derecho, Vol. 38, N² (2011), pp. 279-310.

MAURACH, Reinhart, Derecho Penal. Parte General. T.I, Trad. BOFILL, Jorge; AIMONE, Enrique, séptima edición, Buenos Aires: Astrea, 1994.

MIRA BENAVENT, Javier, "El derecho penal ante el fin de ETA: la cuestión de la criminalización de su entorno político e idelógico", Hermes. Pentsamendu Eta Historia Aldizkaria, $\mathrm{N}^{\circ} 45$ (2013), pp. 4-14.

MORAL DE LA ROSA, Juan, Aspectos penales y criminológicos del terrorismo, Madrid: Centro de Estudios Financieros, 2005.

PÉREZ CEPEDA, Ana, "Definición del delito de terrorismo como un delito internacional", en: SERRANO PIEDECASAS, José Ramón; DEMETRIO, Eduardo (Dirs.). Terrorismo y Estado de derecho, Madrid: Iustel, 2010, pp. 53-79.

QUINTERO OLIVARES, Gonzalo, "La criminalidad organizada y la función del delito de asociación ilícita”, en: FERRÉ, Juan Carlos y ANARTE, Enrique (Eds.), Delincuencia organizada. Aspectos penales, procesales, y criminológicos, Huelva: Publicaciones Universidad de Huelva, 1999, pp.177-190.

REINARES, Fernando, "Conceptualizando el terrorismo internacional", ARI No 82 (2005), en: http://www.realinstitutoelcano.org/

, "Características y formas del terrorismo político en las sociedades industriales avanzadas”, Revista Internacional de Sociología, N 5, mayo-agosto (1993), pp. 3567.

RODRÍGUEZ SÁNCHEZ LARA, Gerardo; NIETO MUÑOZ, Judith, "El terrorismo como método del crimen organizado en México", en BENÍTEZ, R., Crimen organizado e Iniciativa Mérida en las relaciones México-Estados Unidos, México: Colectivo de Análisis de la Seguridad con Democracia, CASEDE, 2010, pp. 87-95.

SALINERO, Sebastián, "El crimen organizado en Chile. Una aproximación criminológica al perfil del delincuente a través de un estudio a una muestra no representativa de condenados por delitos de tráfico de estupefacientes", Revista Política criminal, Vol. 10, No 19 (Julio 2015), Art. 2, pp. 25-55.

SILVA SÁNCHEZ, Jesús, "La intervención a través de organización ¿Una forma moderna de participación en el delito?”, en: CANCIO, Manuel y SILVA, Jesús. Delitos de organización, Montevideo: Bs Aires, BdF, 2008, pp. 87-134.

TERRADILLOS BASOCO, Juan, "El Estado de derecho y el fenómeno del terrorismo" en: SERRANO PIEDECASAS, José Ramón; DEMETRIO, Eduardo (Dirs.). Terrorismo y Estado de derecho, Madrid: Iustel, 2010, pp. 271-292.

TORRES VÁSQUEZ, Henry, "El concepto de terrorismo. Su inexistencia o inoperancia: La apertura a la violación de derechos humanos", Diálogos y Saberes. Investigaciones en derecho y ciencias sociales, $\mathrm{N}^{\circ} 32$ (2010), pp. 77-90.

VACAS FERNÁNDEZ, Félix, El terrorismo como crimen internacional, Valencia: Tirant Monografías 750, 2011.

VAN DIJCK, Maarten, "Discussing Definitions of Organized Crime: Word Play in Academic and Political Discourse ”, Humsec Journal, Issue 1 (2007), pp. 65-90.

VILLEGAS, Myrna, "Los delitos de terrorismo en el Anteproyecto de Código Penal", Revista Política Criminal, N², A3 (2006), pp.1-31.

" "Estado de excepción y antiterrorismo en Chile. Criminalización de la protesta social con especial referencia a los indígenas", Revista de Derecho Penal y Criminología. Año III, N6 (2013), pp. 3-25. 
Polít. crim. Vol. 11, № 21 (Julio 2016), Art. 6, pp. 140-172.

[http://www.politicacriminal.cl/Vol_11/n_21/Vol11N21A6.pdf]

, “Terrorismo: ¿Crimen Organizado?. Análisis comparado”, Anales de la Facultad de Derecho, Universidad de Chile, 2004, pp. 227-248.

, "Convención Interamericana contra el terrorismo: Entre la involución de las garantías y la desprotección de los derechos humanos", Revista de Derecho y Humanidades, $\mathrm{N}^{\circ} 9$ (2002-2003), pp.175-201.

"Terrorismo: un problema de Estado. Tratamiento jurídico del terrorismo en la legislación comparada. Especial referencia a los delitos de terrorismo en las legislaciones de Chile y España", 2002, en: www.cybertesis.cl

ZAFFARONI, Raúl, "El antiterrorismo y los mecanismos de desplazamiento" en: SERRANO PIEDECASAS, José Ramón; DEMETRIO, Eduardo (Dirs.). Terrorismo y Estado de derecho, Madrid: Iustel, 2010, pp. 361-380.

ZÚÑIGA RODRÍGUEZ, Laura, "Criminalidad de empresa, criminalidad organizada y modelos de imputación penal”, en FERRÉ, Juan Carlos y ANARTE, Enrique (Eds.) Delincuencia organizada. Aspectos penales, procesales y criminológicos, Huelva: Publicaciones Universidad de Huelva, 1999, pp. 199- 235. 